\title{
Distinct representation of cue-outcome association by D1 and D2 neurons in the olfactory striatum
}

\author{
Nuné Martiros, Spencer E. Kim, Vikrant Kapoor, Venkatesh N. Murthy* \\ Department of Molecular \& Cellular Biology and Center for Brain Science, Harvard University, Cambridge, MA, USA. \\ *Correspondence: vnmurthy@fas.harvard.edu
}

\section{ABSTRACT}

Positive and negative associations acquired through olfactory experience are thought to be especially strong and longlasting. The conserved direct olfactory sensory input to the ventral striatal olfactory tubercle (OT) and its convergence with dense dopaminergic input to the OT could underlie this privileged form of associative memory, but how this process occurs is not well understood. We imaged the activity of the two canonical types of striatal neurons, expressing D1 or D2 type dopamine receptors, in the OT at cellular resolution while mice learned odor-outcome associations ranging from aversive to rewarding. D1 and D2 neurons both responded to rewarding and aversive odors. D1 neurons in the OT robustly and bidirectionally represented odor valence, responding similarly to odors predicting similar outcomes regardless of odor identity. This valence representation persisted even in the absence of an instrumental response to the odors and in the absence of the outcomes, indicating a true transformation of odor sensory information by D1 OT neurons. In contrast, D2 neuronal representation of the odor-outcome associations was weaker, contingent on an instrumental response by the mouse, and D2 neurons were more selective for odor identity than valence. Stimulus valence coding in the OT was not modality invariant, with separate sets of D1 neurons responding to odors and sounds predicting the same outcomes, suggesting that integration of multimodal valence information happens downstream of the OT. Our results point to distinct representation of identity and valence of odor stimuli by D1 and D2 neurons in the OT.

\section{INTRODUCTION}

Assigning value to stimuli in the external environment and subsequently adjusting behavior on the basis of those learned values is a primary function of the nervous system. Understanding this process is especially important because certain associations result in maladaptive behaviors such as compulsions, binge eating, and drug addiction (Everitt and Robbins, 2005, Keiflin and Janak, 2015, Wise and Koob, 2014). Olfaction or chemosensation is thought to have preceded other sensory modalities in evolution as the first direct link of the nervous system to the external environment (Ache and Young, 2005, Kaas, 2008, Schneider, 2013) to allow for such stimulus value learning. Olfactory sensory pathways to the forebrain remained relatively conserved across phyla while visual, auditory, and somatosensory information was routed in polysynaptic pathways through thalamus and cortex (Purves D, 2001, Schneider, 2013). Due to this, the olfactory system has uniquely direct access to limbic centers of the brain. In particular, the olfactory tubercle (OT), a ventral basal ganglia structure known to be involved in reward processing (Gadziola et al., 2015, Hagamen et al., 1977, Ikemoto, 2003, 2007, Wesson and Wilson, 2011, Zhang et al., 2017), is a direct recipient of a stream of olfactory input from a distinct class of olfactory bulb neurons, the tufted cells (Igarashi et al., 2012). The OT is one of the main targets of sensory projections from the olfactory bulb and cortex, and concurrently receives dense dopaminergic input from the ventral tegmental area (VTA), similar to other ventral striatal regions - suggesting that the OT is ideally suited to integrate these inputs to assign valence to olfactory stimuli based on experience. It has been described in humans that olfactory sensory cues may be more powerfully linked to emotional memories than other types of sensory cues (Miles and Berntsen, 2011, Pointer and Bond, 1998, Reid et al., 2015), and that odor associations can be important in psychological health and disease (Daniels and Vermetten, 2016, Herz, 2016), suggesting a possible specialized form of olfactory memory in limbic regions such as the OT.

The OT has been implicated in motivation as well as olfactory processing (Hagamen et al., 1977, Ikemoto, 2007, Koob et al., 1978, Koob and Volkow, 2010, Wesson and Wilson, 2011, Wright and Wesson, 2021). As an example, self- 
administration of cocaine into the OT was found to be even more addictive than administration into nucleus accumbens, a key region known to be involved in reward, motivation, and addiction (Ikemoto, 2003). Stimulation of OT neurons or dopaminergic terminals in the OT has been shown to be effective in inducing odor preference or approach (Fitzgerald et al., 2014, Gadziola et al., 2020, Zhang et al., 2017). Electrophysiological recordings in the OT have revealed that OT neurons differentiate between rewarded and unrewarded odors in a go/no-go task, and quickly track changing odor-outcome contingencies (Gadziola et al., 2015, Millman and Murthy, 2020). These effects may extend to humans with elevated OT activity and development of place preference in response to attractive odorants (Midroit et al., 2021). Moreover, the OT appears to be the olfactory processing site most strongly involved in tracking odor-outcome associations, as direct comparison to recordings in posterior piriform cortex revealed weaker representation of odor-reward contingency (Gadziola et al., 2020, Millman and Murthy, 2020). The much higher density of dopaminergic input to the OT as compared to piriform cortex is likely relevant in differentiating the functions of these two parallel olfactory processing regions.

This evidence establishes OT as a key region likely involved in learning odor-outcome associations and assigning emotional tags to odors. However, many questions remain unanswered regarding the nature of the information encoded by OT neurons and the role of the different neuronal types within the OT in this function. OT is a part of the ventral striatum and consists of spiny projection neurons (SPNs). Striatal SPNs are roughly divided into D1-type and D2type dopamine receptor expressing SPNs, and these two groups of SPNs also have different output projection patterns (Bolam et al., 2000, Gerfen and Surmeier, 2011). This differentiation of OT projection neurons into D1 and D2 type is especially relevant when considering the role of dopaminergic input in shaping odor valence representation. D1 and D2-type dopamine receptors are thought to differ in terms of their response to dopamine, in particular, the plasticity rules regulated by dopamine (Gerfen and Surmeier, 2011, Lovinger, 2010, Nicola et al., 2000). To address the role of these neuronal subtypes in the OT, we conducted the first (to our knowledge) two-photon imaging of specific neuronal types in the OT in behaving mice. We then used experimental manipulations to address questions about the role of the OT and these neuronal types in the stimulus identity-valence-response transformation function.

\section{RESULTS}

To investigate the role of D1 and D2 receptor expressing neurons in the OT in odor valence learning we imaged the activity of these neuronal populations in the OT using multiphoton microscopy, while mice learned to associate odors with aversive or rewarding outcomes. Adenoassociated virus that expresses calcium indicator GCaMP7s in the presence of Cre recombinase virus was injected into the right OT of Drd1-Cre and Adora2A-Cre mice and a $1 \mathrm{~mm}$ cannula was implanted targeting the OT (Fig. 1A, Fig. S1B). After recovery, a GRIN lens was placed in the cannula, mice were water restricted, habituated to head-fixation, and trained on an odor-outcome conditioning task. Five monomolecular odors were coupled with graded outcomes ranging from aversive to rewarding (strong airpuff to nose, weak airpuff to nose, no outcome, small water drop, large water drop) (Fig. 1B). Odor-outcome assignments were counterbalanced across mice and the five trial types were randomly interspersed across training sessions with 30 trials per day of each of the five odors. In each trial, the odor was presented for $1.5 \mathrm{~s}$ and the outcome (water or airpuff) was presented 1.3s after odor onset. Prior to the first day of odor-outcome training mice underwent a pre-training session (day 0 ) in which the airpuff and water outcomes were presented without any odors. In day 1 of odor-outcome training, mice quickly learned the odor-outcome contingencies and began licking in anticipation of water delivery in the period after odor onset prior to water delivery (Fig. 1C). By training day 2, the anticipatory licking rate of implanted Drd1-Cre and Adora2A-Cre mice in response to rewarded odors $4 \& 5$ was similarly high and little anticipatory licking was observed for non-rewarded odors 1-3 (Fig. 1D).

\section{OT neuronal activity robustly and bidirectionally reflects odor-outcome contingency}

D1 neurons in six Drd1-Cre mice ( $88 \pm 13$ neurons per mouse) and D2 neurons in six Adora2A-Cre mice ( $56 \pm 18$ neurons per mouse) developed both excitatory and inhibitory responses to the task odors across days of training (Fig. 1E-G), 
with the most rewarded odor typically eliciting the strongest neuronal responses after training. Task-related activity of the population of D1 neurons we recorded was strikingly similar during the two aversive trial types (Fig. 2A, columns 1-2) and similar during the two rewarded trial types (Fig. 2A, columns 4-5) although the identity of the odorants presented during these trials varied across mice. Overall, neurons followed similar activity patterns during the two rewarded trial types and during the two aversive trial types (Fig. 2B-C, Fig. S2). Correlation between the activities of groups of stimulus-responsive neurons in each mouse, measured by cosine similarity, was higher for same outcome trials than for opposite outcome trials after the first training day (Fig. 2D). D1 neurons were more likely to become activated in response to rewarding odors than aversive odors ( $p<0.01$ paired t-test for odor $1 \mathrm{v}$ odor 5 in six mice). Interestingly, counter to our initial expectation that D2 neurons may be more likely to respond to aversive odors D2 neurons were no more likely to become activated in response to aversive stimuli than to rewarding stimuli (mean of $20 \%$ in 6 mice for aversive odor 1 and 34\% for rewarding odor $5, p=0.14$ paired t-test), with a trend in the opposite direction (Fig. 2E).

\section{Individual D1 neurons are more likely to encode odor valence and D2 neurons more likely to encode odor identity}

By using graded odor-outcome associations, we aimed to disambiguate neuronal coding for odor valence, odor motivational salience, and odor identity. We hypothesized that, in our task, idealized valence coding neurons would exhibit similar responses to odors of similar valence (Fig. 3A, rows 1-2), salience coding neurons would exhibit similar responses to odors of high relevance regardless of whether the outcome positive or negative (Fig. 3A, row 3 ), and odor identity responsive neurons would be most likely to respond to a single individual odor (Fig. 3A, last row). In our dataset, the prevalence of neuronal responses consistent with odor salience coding was very low ( 3 of 529 D1 neurons were activated for high motivational salience odors 1 and 5, but not odors 2-4, as compared to 51 neurons activated for positive valence odors 4 and 5 , but not odors 1-3, $p<0.000001$ Fisher's Test for D1 and D2 neurons). This indicates that OT neuronal populations are very sensitive to the sign of the odor valence (aversive or rewarding). Thus, we focused the remainder of our analysis on odor valence or odor identity coding by D1 and D2 neurons. We assigned each significantly responsive neuron a valence score by computing a normalized difference between the neuron's activity in response to odors of opposite valence and odors of same valence (Fig. 3B, see Methods). Identity scores were also calculated for each neuron by comparing the activity of the neuron to its most preferred stimulus to its next most preferred stimulus (see Methods). Individual neurons varied widely in valence and identity scores, with some neurons having high identity scores and low valence scores (Fig. 3C) and other neurons having high valence scores and low identity scores (Fig. 3D). Interestingly, identity scores of D1 neurons decreased with days of training ( $<<0.05$ for day 1 versus 4, Wilcoxon rank-sum test), while identity scores of D2 neurons trended to increase with training (Fig. 3E, left and middle). After training, identity scores of D2 neurons were significantly higher than those of D1 neurons (Fig. $3 E$, right, $p<0.001$ rank sum test), with more D2 neurons exhibiting clear isolated activity in response to an individual odor. In contrast, odor valence coding scores of D1 neurons significantly increased with days of training ( $p<0.0001$ for day 1 versus 4, Wilcoxon rank-sum test) while those of D2 neurons did not (Fig. 3F, left and middle). After training, odor valence coding scores of D1 neurons were significantly higher than those of D2 neurons (Fig. 3F, right, p < 0.000001 rank sum test).

\section{D1 OT neurons encode odor valence in the absence of an instrumental response or outcomes}

In the odor-outcome association task, both odors of positive valence were accompanied by licking responses and water drop delivery, and both odors of negative valence were accompanied by airpuff delivery. As such, these trial types shared instrumental responses and unconditioned stimuli that likely contributed to the shared outcome-related neuronal responses we observed. In order to test whether activity of OT neurons reflected true valence coding of the odor stimulus, we constructed a probe session with two distinct training blocks. Block 1 of the session proceeded as previously described. After this first block, a two-minute break was introduced in which mice received $2 \mathrm{~mL}$ of free 
water droplets and became sated on water. Block 2 of the imaging was then conducted where mice did not lick in response to odor presentations and all outcomes (water and airpuff) were omitted (Fig 4A). As compared to Block 1 , we found that mice very rarely exhibited anticipatory licking in response to the rewarded odors (Fig. 4B). Mice licked an average of $4.8 \pm 0.1$ times in odor 5 trials in Block 1 and an average of $0.2 \pm 0.06$ times in odor 5 trials in Block 2 (p $<0.000001$, rank sum test). In the following imaging data analysis, any Block 2 trials in which mice exhibited non-zero licks ( $5 \%$ of trials) were excluded.

In Block 2, in the absence of licking and outcomes, D1 neuronal responses to odors of previously learned negative valence (Fig. 4C, columns 1-2) were still highly similar and responses to odors of previously learned positive valence were similar (Fig. 4C, columns 4-5), as in the full task condition (Fig. 2A). The Euclidean distance between D1 population activities in response to odor pairs of opposite valence was $68 \%$ greater than between odor pairs of same valence. Principal components of neuronal activity and cosine similarity measures further confirmed maintenance of strong valence representation in D1 neurons in Block 2 (Fig. 4D-E). However, valence representation was no longer present in the D2 neuronal population in Block 2 (Fig. S3 and 4E), and only 12\% greater Euclidian distance in the population activity remained in odor pairs of opposite than same valence.

Individual neuron valence coding scores of D1 neurons decreased significantly in Block 2 as compared to the full task condition (Fig. 4F, left, rank sum test $p<0.0001$ ) indicating that the presence of the licking response, the water and airpuff outcomes, as well as the presence of a motivated thirsty state in the mouse contributed significantly to the odor-outcome related activity of the D1 neurons. However, the mean of the distribution of the D1 valence scores in Block 2 remained above zero ( $p<0.000001$, Wilcoxon signed rank test), with many D1 neurons maintaining strong valence representation. Odor valence scores of D2 neurons decreased in this sated condition (Fig. 4F, right, $p<0.0001$ rank sum test), and the mean of the distribution of valence scores of D2 neurons in Block 2 was no longer significantly different from zero. Valence scores of D1 neurons were significantly higher than valence scores of D2 neurons in Block 2 ( $p<0.01$ rank sum test). Concurrently, with the omission of licking and outcomes, odor identity coding scores of both D1 and D2 neurons increased in Block 2 (Fig. 4G, $p<0.01$ rank sum test).

\section{Stimulus valence coding by D1 OT neurons is not modality invariant}

To further interrogate the stimulus valence coding property of OT neurons, implanted Drd1-Cre mice $(n=6)$ and Adora2A-Cre mice $(n=4)$, which had been previously trained on the five odor-outcome conditioning task, were trained on a new task in which sound associations were introduced. Odors 1 and 5, which had already been learned to be associated with the strong airpuff outcome and large water drop delivery were combined with two sound tones $(5 \mathrm{kHz}$ and $12 \mathrm{kHz}$ ) predicting the same aversive and rewarding outcomes (Fig. 5A). These sound stimuli were selected after a pilot behavioral study in a separate cohort of mice with no implants, designed to produce similar learning and anticipatory licking rates as the odor stimuli. After one training day with the new sound stimuli, the anticipatory licking rates of ten mice in response to the rewarded sound stimulus were similar to that of the previously learned rewarded odor stimulus (Fig. 5B). After three days of training on the new odor-sound associations, a probe session as described previously was conducted, in which mice were sated on water midway in the session and the odor and sound stimuli were then presented in Block 2 in the absence of licking or outcomes (Fig. 5A).

In the stimulus-only condition in Block 2, we found that the same D1 neuronal populations which had previously strongly maintained similar activity patterns in response to odors of similar valence (Fig. 4C) did not do so for odor and sound pairs of identical valence (Fig. 5C). In the full-task condition when licking and outcomes (water or airpuff) were present, neuronal activity was similar during rewarding and aversive trials (Fig 5I, Fig. S4), but this similarity was lost in the stimulus-only condition. Only 5\% greater Euclidian distance remained between D1 population activity in response to odor-sound pairs of opposite valence as compared to odor-sound pairs of same valence, unlike the $68 \%$ difference found in Block 2 of the five odor task. Interestingly, although 24\% of D1 neurons were significantly activated during at least one of the sound trial types in Block 2, these neurons were largely non-overlapping with those which responded 
to the odor stimuli (Fig. 5D). We then directly compared the activity of neurons which were responsive to odors 1 and 5 in response to the matched valence odor stimuli (odors 2 and 4, in odor-odor task) and the matched valence sound stimuli (sounds 1 and 2, in odor-sound task). We found that aversive odor 1 responsive neurons became highly activated when aversive odor 2 was presented in Block 2 of the odor-odor task, but this was not the case when sound tone 1 was presented in the odor-sound task (Fig. $5 \mathrm{E}$, orange, $\mathrm{p}<0.000001$ rank sum test for difference between odorodor and odor-sound). Similarly, rewarding odor 5 responsive neurons became highly activated when rewarding odor 4 was presented in Block 2 of the odor-odor task, but this was not the case when rewarding sound tone 2 was presented (Fig. 5E, green, $p<0.000001$ rank sum test). We also calculated valence scores for these neurons in the odor-odor task and the odor-sound task. In the standard task condition with licking and outcomes (Fig. 5F), as well as in the sated condition with no licking or outcomes (Block 2, Fig. 5G), the valence scores of D1 neurons in the odor-sound task were significantly lower than the valence scores of the neurons in the odor-odor task ( $p<0.0001$, rank sum test). This occurred despite the presence of similar levels of anticipatory licking in response to the rewarded sound tone, and even though the odor and sound related outcomes in the odor-sound task were identically matched while those in the odor-odor task were not.

Finally, we compared the principal components of D1 neuronal population activity in response to the five odors in Blocks 1 and 2 in the odor-odor task and activity in response to the odor sound stimuli in Blocks 1 and 2 in the odorsound task. Principal components of D1 neuronal populations were very similar in odors predicting similar outcomes in the typical task condition (Fig. $5 \mathrm{H}$, top) and the sated condition with no licking or outcomes (Fig. 5H, bottom). However, there was no such clear similarity of D1 neuronal population principal components in response to odors and sound tones predicting identical outcomes (Fig. 5I), suggesting distinct neuronal activity trajectories in response to each of the four stimuli used in the odor-sound task.

\section{DISCUSSION}

The results of these experiments offer key insights into the function of OT neuronal circuitry during odor association learning. We find some surprising similarities and some key differences in the neuronal responsivity of D1 and D2 type OT neurons, in the first single neuron imaging experiments of specific neuronal subtypes in the OT. We found that D1 neuronal populations clearly responded to both positive and negative odor valence. This is the first demonstration of bidirectional odor valence coding by OT neurons, as no previous real-time recordings of OT neurons in response to aversive valence odors have been reported. We therefore can conclude that the OT is likely to be involved in learning about both positive and negative odor associations, rather than the alternative possibilities that the OT is only involved in learning rewarded odor associations, or that it encodes odor salience rather than signed odor valence. We note that a higher proportion of neurons was active in response to the rewarded odors than the aversive odors; however, this may be an effect of possible high value of the water reward outcome in water restricted mice as compared to the aversiveness of a relatively harmless airpuff to the nose. Surprisingly, similar proportions of D1 and D2 neurons responded to the five task odors, challenging our initial hypothesis that D2 neurons may respond more strongly to negatively reinforced odors, based on immediate early gene expression results (Murata et al., 2015, Murata et al., 2019). This suggests that models of dopamine acting to potentiate responses of D1R expressing neurons and depotentiate responses of D2R expressing neurons or dopamine dips potentiating D2R expressing neurons (Bamford et al., 2018, lino et al., 2020, Surmeier et al., 2007, Yagishita et al., 2014) are not sufficient to account for the neuronal activity we observed, in accordance with a more complex interplay between dopamine and the two striatal neuronal types (de Jong et al., 2019, Kutlu et al., 2021).. Other inputs to D1 and D2 type neurons in the OT, including strong inputs from piriform cortex (White et al, 2019), could also create differentiated activity in these neurons.

We then addressed a long-standing question about the factors driving the responses of OT activity in odor-outcome behavioral paradigms. In previous OT recording experiments, go/no-go tasks were used where licking in response to the rewarded odors was required. In our classical conditioning task, mice similarly exhibited anticipatory licking at the 
onset of the rewarded odors, although the water delivery was not contingent on this response. In all of these conditions, the odor presentation itself was in every case coupled with the motor licking action of the mouse. Thus, it was unclear whether the neuronal activity recorded occurred as a result of the odor stimulus or the instrumental response. Previously, it was reported that the onset of the recorded neuronal activity preceded the onset of the licking action by $200 \mathrm{~ms}$ (Gadziola et al., 2015, Millman and Murthy, 2020); however, this time lag is well within the time range typically seen in motor preparatory neuronal activity (Svoboda and Li, 2018, Tanaka et al., 2021) and could still be linked to the licking action or its preparation. To address this confound, we sated the mice on water and omitted the outcomes associated with the odors. We observed that in $95 \%$ of the trials in this condition mice exhibited zero licks and we analyzed neuronal activity from only these trials. We observed that D1 OT neurons continued to respond to the learned odors and continued to strongly differentiate odor valence in the absence of licking or outcomes. This finding indicates that the critical sensory transformation step of integrating odor identity information and outcome information takes place in the OT D1 neurons, and that the odor-outcome related activity seen in our recordings and previous recordings are not the result of unintended correlations with movement. This is especially notable given the low motivational state of the sated mouse in this experimental condition, suggesting that D1 OT neurons, at least temporarily, maintain odor valence memory even in conditions when the outcomes associated with the learned odors become less consequential. It should be noted, however, that in the condition where licking and water and airpuff delivery were present, the odor-outcome representation in D1 and D2 neurons was enhanced as compared to the stimulus-only sated condition. This indicates far enhanced OT engagement during conditions in which the mice were motivated and behaving, consistent with other reports of increased neuronal activity modulation in sensory regions in attentive behaving mice as compared to passive stimulus presentation conditions (Busse et al., 2017, Carlson et al., 2018, Pakan et al., 2018).

Our findings on the activity of OT D2 neurons provide an interesting contrast to the robust valence coding property of D1 neurons. While D2 neuronal populations differentiated between rewarded and aversive outcomes in the task condition involving licking and outcomes, this representation was significantly weaker than that of D1 neurons and disappeared in the stimulus-only condition when licking and outcomes were omitted. This result contrasts with photometry data in which reward contingency information was not observed in average D2 population activity in a go/no-go task (Gadziola et al., 2020), suggesting it is possible to differentiate rewarded trials in non-averaged D2 neuronal activity in a condition when the instrumental response is present. However, our data does demonstrate that reward contingency information is more readily represented by D1 neurons than D2 neurons. Individual D2 neurons were much more likely to respond to an individual odor of the five task odors and exhibit little responsivity to any of the other four odors, suggesting odor-identity rather than odor-valence responsivity. Increased training resulted in increases in the valence-coding scores of D1 neurons and decreases in their odor-identity coding scores, while the opposite pattern was observed in D2 neurons, with increased odor-identity coding scores with training.

How D1 and D2 neuronal representations of learned odors diverge based on inputs to these neurons and the effect of dopamine onto them, and how they then subsequently shape behavior as they influence downstream targets are both important areas to investigate. Cre-expressing neurons from the Drd1-Cre and Adora2A-Cre mouse lines used in our imaging experiments have been previously shown to project via the distinct direct and indirect striatal output pathways (Gerfen et al., 2013), confirmed in our laboratory (Fig. S1A), and as such have opposing overall effects on thalamus and cortex, potentiating behavioral output and inhibiting it, respectively. Given the relatively weak odor-outcome representation by OT D2 neurons, the question also remains whether these neurons play a significant role in odoroutcome association learning, or whether D1 OT neurons predominantly contribute to this function.

Finally, we used auditory stimuli predicting matching rewarding and aversive outcomes as a comparison point for the odor responses we observed in the OT. First, we conjectured that if the neuronal responses we observed were most closely related to the outcome and motor licking response than to the odors themselves, we would observe similar OT activity in response to odors and sounds predicting the same outcomes. However, if the neuronal activity was more closely related to the presence of the odor stimuli, we would not observe the same activation in response to sounds. 
Secondly, auditory cortex projects to other striatal regions (Chudler et al., 1995, Nagy et al., 2006, Nagy et al., 2005, Reig and Silberberg, 2014) and has been reported to project to other sensory areas (Budinger and Scheich, 2009, Cappe et al., 2009) suggesting possible multimodal integration. Auditory responses in $19-37 \%$ of OT neurons have been observed in the past suggesting that auditory information directly or indirectly can impact OT neuronal activity (Varga and Wesson, 2013, Wesson and Wilson, 2010). However, whether stimulus-valence representation extends to multimodal stimuli in the OT has not been tested. Consistent with previous results, we found that $24 \%$ of D1 neurons and $14 \%$ of D2 neurons were activated in response to one of the sound tones. However, unlike the large overlap and similarity between neuronal activity in response to different odors predicting similar outcomes, we found little overlap between neurons responding to odors and sounds predicting identical outcomes. This finding points to two conclusions. First, corroborating our previous result, we can conclude that the odor valence related OT activity was not primarily a result of the licking response of the mouse. We demonstrate that behaviorally, the anticipatory licking rates of the mice in response to the rewarded odor stimulus and the rewarded sound stimulus are similarly high after training, yet stimulus-outcome representation in the OT during the odor-sound task is minimal in the period prior to outcome delivery even in the presence of matched anticipatory licking rates. Second, we can conclude that stimulus valence representation by D1 OT neurons is limited to olfactory stimuli, and does not generalize to multimodal stimuli. Hence, while auditory related responses in OT do occur and some supra-additive effects of odor and sound stimuli have been reported (Wesson and Wilson, 2010), the integration of multimodal stimuli predicting behaviorally outcomes is likely to occur downstream of the OT. This finding is relevant when considering the possible specialized role of limbic brain regions such as the olfactory tubercle to store emotionally charged odor memories, a property that may be unique to the sensory modality of olfaction.

In summary, we find that D1 OT neurons selectively and bidirectionally encode learned odor valence, unlike D2 neurons which are more likely to encode odor identity. We also demonstrate, for the first time, that even when the instrumental response to rewarded odors is eliminated, OT D1 neurons continue to robustly encode odor valence suggesting that this stimulus to valence transformation by the OT precedes the motor action itself. This also suggests that OT odor valence representation is not correlational in nature, but likely serves to inform downstream brain regions of the value of odor stimuli. Finally, we find that stimulus valence representation by OT neurons is limited to olfactory stimuli suggesting a specialized role of the OT in assigning emotional tags to odors based on previous experience. Further investigation into the relative contributions of D1 and D2 OT neurons to odor association learning and the neural mechanisms that result in the differential responses of these neuronal types is required. These neuronal imaging results suggest a specialized role for the OT in odor valence memory, and further studies can be conducted to assess the causal contribution of the OT to the hypothesized unique emotional qualities of olfactory memory.

\section{ACKNOWLEDGMENT}

We thank Dr. Naoshige Uchida and Dr. Mitsuko Uchida for their helpful guidance throughout this project and comments on the manuscript. We thank Dr. Hao Wu for his help in establishing the Python-based, ScopeFoundry behavioral control system for the experiments. We also thank Selina Qian and Rebecca Fisher, for helping with animal colony maintenance and habituation, and helpful discussions. This work was supported by grants from the NIH (R01DC017311, F32DC017891) and a Bipolar Disorder Seed Grant from the Harvard Brain Initiative.

\section{MATERIALS AND METHODS}

\section{Animals}

Adult male and female heterozygous B6.FVB(Cg)-Tg(Drd1-cre)EY262Gsat/Mmucd and B6.FVB(Cg)-Tg(Adora2acre)KG139Gsat/Mmucd (MMRRC) mice were 2-6 months of age at the start of the experiments. Due to the highly 
consistent co-localization of A2A receptors and D2 dopamine receptors in the striatum, no colocalization of A2A receptors with D1 dopamine receptors (Gerfen and Surmeier, 2011, Svenningsson et al., 1998), and previously established use of A2A-Cre mice for indirect pathway specific manipulation (Cui et al., 2013), we proceeded with the use of Adora2A-Cre mice to image D2-type neurons. All experiments were conducted with approved protocols and in accordance with Harvard University Animal Care Guidelines.

\section{Cannula Assembly}

Custom designed cannula were assembled in house. $6.2 \mathrm{~mm}$ length $1.1 \mathrm{~mm}$ diameter ultra-thin wall biocompatible polyimide tubing (MicroLumen) which was demonstrated to cause minimal inflammatory response in the brain (Bocarsly et al., 2015) was used for the walls of the cannula. 150 $\mathrm{m}$ thickness quartz coverslips (Electron Microscopy Sciences) were cut to $1 \mathrm{~mm}$ diameter disks in a laser cutter and used as the floor of the cannula. Cut quartz disks were held with the assistance of vacuum under the view of a surgical microscope, attached to the polyimide tube with Norland Optical Adhesive NOA 68 (Edmund Optics), and adhesive was cured with UV light source (ThorLabs). Directly prior to surgical implantation cannula were inspected and disinfected with the use of the UV light source.

\section{Surgery}

Naïve mice underwent surgical virus injection, cannula implantation, and head fixation plate implantation, prior to any behavioral training. Mice were anesthetized with an intraperitoneal injection of a mixture of xylazine $(10 \mathrm{mg} / \mathrm{kg})$ and ketamine $(80 \mathrm{mg} / \mathrm{kg})$ and placed in a stereotaxic apparatus. A $1.4 \mathrm{~mm}$ craniotomy was performed at $1.5 \mathrm{~mm} \mathrm{AP}, 1.3 \mathrm{~mm}$ $\mathrm{ML}$ in the right hemisphere. A $22 \mathrm{G}$ needle was used to suction $2 \mathrm{~mm}$ below the brain surface prior to virus injection. A pulled glass micropipette attached to a nanoinjector (MO-10, Narishige) was used to inject 400nL of pGP-AAV9-synFLEX-jGCaMP7s-WPRE (Addgene) virus at a depth of $4.8 \mathrm{~mm}$ DV at a rate of $100 \mathrm{~nL} / \mathrm{min} .5$ minutes after the injection was completed, the glass pipette was raised out of the brain over the course of another 5 minutes. The sanitized cannula was then held lightly with a dental paper point inserted into its center and attached to the stereotaxic arm. The cannula was lowered over the course of 10 minutes to a depth of $4.9 \mathrm{~mm}$ DV. The cannula was secured onto the skull with cyanoacrylate glue and a head fixation plate was also glued to the skull behind the cannula. Dental cement (MetaBond) was then used to cover the skull and headplate. The opening of the cannula was covered with a silicone sealant (KwikSil). Mice were single housed after surgery. After a period of four weeks to allow for virus expression and the reduction of the inflammatory response to the insertion of the cannula, a $1 \mathrm{~mm}$ diameter, $3.4 \mathrm{~mm}$ long $0.5 \mathrm{NA}$ Gradient-Index (GRIN) lens (ThorLabs) was inserted into the cannula and behavioral training and imaging begun.

\section{Behavioral Training}

Mice were water restricted to reach $85-90 \%$ of their initial body weight and provided approximately $1-1.5 \mathrm{~mL}$ water per day in order to maintain desired weight. Mice were habituated to head fixation and drinking from water spout prior to initial training session. In the pre-training (day 0), mice were provided large water drops (20 $\mu \mathrm{L})$, small water drops $(10 \mu \mathrm{L})$, strong airpuff (10 PSI), and weak airpuff (5 PSI) in identical trial structure as full five odor conditioning task, but odors were not used. Each mouse was then assigned five odor-outcome contingencies with the monomolecular odorants hexanal, limonene, anisole, eucalyptol, and heptanal. Odors were delivered via a custom-built olfactometer as described previously (Soucy et al., 2009) with a $1.5 \mathrm{~L} / \mathrm{min}$ flow rate at a concentration of $20 \%$ for $1.5 \mathrm{~s}$ each. Odoroutcome contingencies were assigned so as to equally or close to equally counterbalance the odor-outcome contingencies across each cohort of mice. 
In days 1-4 of training, each of the five odors and associated outcomes were provided 30 times with 20s inter trial intervals. In $10 \%$ of trials ( 3 trials of each trial type), the outcomes were omitted; however, this number of trials was not later found to be sufficient for the analysis of neuronal activity. Trial types were interspersed randomly across the session, with the constraint that equal numbers of each trial type occurred in the first and second half of each session to ensure equal trial type representation for the duration of each imaging session. Licking of the water delivery spout was measured throughout training and imaging with the use of a capacitance sensing Arduino circuit. Behavioral events control and recording was conducted with Python with adapted use of the ScopeFoundry platform (scopefoundry.org) and National Instruments DAQ hardware.

Prior to Block 2 in the probe session in day 5 of training, $2 \mathrm{~mL}$ of free water was provided to the headfixed mouse over the course of 2 minutes. 15 trials of each trial type were then presented in identical task structure as in Block 1, however all water and airpuff outcomes were omitted.

Training in the odor-sound task occurred 1-2 days after the completion of the five-odor task training. Odors 1 and 5 with strong airpuff and large water drop outcomes were preserved, and $5 \mathrm{kHz}$ and $12 \mathrm{kHz}$ sound tones were introduced paired with the same strong airpuff and large water drop outcomes. As in previous task, 30 trials of each condition were randomly interspersed across session time. Onset and duration (1.5s) of the sound stimuli and associated outcomes was identical to that of the odor stimuli. After 3 days of odor-sound task training, a probe session with two blocks was conducted as in the original five odor task.

\section{Two-photon imaging of calcium activity}

A custom-built microscope was used for in vivo imaging as described previously (Kapoor et al., 2016, Petzold et al., 2009). Imaging was conducted at $5 \mathrm{~Hz}$ with an air objective (10x, Leica) at $430 \mathrm{~nm}$ using a Ti:sapphire laser (Chameleon Ultra, Coherent) with a $140-\mathrm{fs}$ pulse width and $80-\mathrm{MHz}$ repetition rate. Image acquisition, scanning, and stimulus delivery were controlled by custom-written software in LabVIEW (National Instruments). Prior to two-photon imaging the position of the GRIN lens and approximate neuronal imaging plane was determined with a camera. The head fixation plate was mounted on an adjustable pitch and roll platform (ThorLabs) which allowed for manual adjustment of the lens angle to parallel alignment with the objective. The depth of the imaging plane was adjusted each day to closely match that of the previous imaging days, capturing the same or highly overlapping neuronal populations across days of training.

\section{Calcium imaging data analysis}

Imaging data was motion corrected with Non-Rigid Motion Correction (NoRMCorre) (Pnevmatikakis and Giovannucci, 2017). The activity of single neurons was then isolated and background subtracted with the use of CalmAn (Giovannucci et al., 2019) followed by manual refinement. The number of putative calcium transient events in each neuron was then

Valence Score $=\frac{\text { mean (differences between opposite valence odors })- \text { mean (differences between same valence odors })}{\mid \text { maximum response }- \text { minimum response } \mid}$

$$
\text { Identity Score }=\frac{\text { strongest odor response-second strongest odor response }}{\text { strongest odor response }}
$$

quantified based on a criterion of activity 3 standard deviations above a temporally proximal baseline lasting longer than 5 frames, and neurons with less than two recorded transients were not used in the analysis. Due to baseline fluorescence fluctuations in single neurons, the activity of each neuron in individual trials was normalized to a $1 \mathrm{~s}$ pretrial baseline to isolate trial event related fluorescence changes. Due to the $5 \mathrm{~Hz}$ imaging rate and following use of a 
minimal locally weighed smoothing filter to reduce noise in recordings, in some cases event triggered changes in fluorescence may appear to begin in 1-2 frames prior to the event time.

Odor valence coding scores and odor identity coding scores were computed for neurons which had significant mean activity deviations of $>30 \%$ from pre-trial baseline as shown below. Distributions of odor valence scores and odor identity scores across neuronal types and task conditions were compared with the non-parametric Wilcoxon rank-sum test. Matrix difference measures of neuronal population activity were conducted by taking the Euclidean norm of the difference between population activity in response to pairs of stimuli used in the task. The mean norm for stimuli pairs of opposite valence was then compared to the mean norm for stimuli pairs of the same valence. Neuronal population activity dimensionality reduction and trajectory analysis was conducted with the use of the DataHigh toolbox (Cowley et al., 2013) with all D1 and D2 neurons collected in the dataset and trial types used as input conditions.

\section{Histological confirmation of imaging site}

After completion of imaging experiments, mice were transcardially perfused, and the brains were removed from the skull. Coronal floating sections were cut using a vibratome (Leica VT1000S). Brain sections were imaged using the Zeiss Axio Scan slide scanner at the Harvard Center for Biological Imaging to visualize the location of GCaMP expression and the location of cannula tip. Brain section images were matched and overlaid with the Paxinos and Franklin Mouse Brain Atlas cross-sections to identify imaging location. Six of eleven implanted Drd1-Cre mice had confirmed OT imaging locations, while in others the tip of the cannula was located in ventral pallidum or nucleus accumbens. Eight of eleven implanted Adora2A-Cre mice had confirmed OT imaging locations, but only six of eight produced satisfactory imaging results. Only mice with confirmed OT imaging locations and successful imaging results were used in later analysis.

\section{REFERENCES}

Ache, B. W. \& Young, J. M. (2005). Olfaction: diverse species, conserved principles. Neuron 48, 417-30.

Bamford, N. S., Wightman, R. M. \& Sulzer, D. (2018). Dopamine's Effects on Corticostriatal Synapses during RewardBased Behaviors. Neuron 97, 494-510.

Bocarsly, M. E., Jiang, W. C., Wang, C., Dudman, J. T., Ji, N. \& Aponte, Y. (2015). Minimally invasive microendoscopy system for in vivo functional imaging of deep nuclei in the mouse brain. Biomed Opt Express 6, 4546-56.

Bolam, J. P., Hanley, J. J., Booth, P. A. \& Bevan, M. D. (2000). Synaptic organisation of the basal ganglia. J Anat 196 ( Pt 4), 527-42.

Budinger, E. \& Scheich, H. (2009). Anatomical connections suitable for the direct processing of neuronal information of different modalities via the rodent primary auditory cortex. Hear Res 258, 16-27.

Busse, L., Cardin, J. A., Chiappe, M. E., Halassa, M. M., McGinley, M. J., Yamashita, T. \& Saleem, A. B. (2017). Sensation during Active Behaviors. J Neurosci 37, 10826-10834.

Cappe, C., Rouiller, E. M. \& Barone, P. (2009). Multisensory anatomical pathways. Hear Res 258, 28-36.

Carlson, K. S., Gadziola, M. A., Dauster, E. S. \& Wesson, D. W. (2018). Selective Attention Controls Olfactory Decisions and the Neural Encoding of Odors. Curr Biol 28, 2195-2205 e4.

Chudler, E. H., Sugiyama, K. \& Dong, W. K. (1995). Multisensory convergence and integration in the neostriatum and globus pallidus of the rat. Brain Res 674, 33-45.

Cowley, B. R., Kaufman, M. T., Butler, Z. S., Churchland, M. M., Ryu, S. I., Shenoy, K. V. \& Yu, B. M. (2013). DataHigh: graphical user interface for visualizing and interacting with high-dimensional neural activity. J Neural Eng 10, 066012.

Cui, G., Jun, S. B., Jin, X., Pham, M. D., Vogel, S. S., Lovinger, D. M. \& Costa, R. M. (2013). Concurrent activation of striatal direct and indirect pathways during action initiation. Nature 494, 238-42.

Daniels, J. K. \& Vermetten, E. (2016). Odor-induced recall of emotional memories in PTSD-Review and new paradigm for research. Exp Neurol 284, 168-180. 
de Jong, J. W., Afjei, S. A., Pollak Dorocic, I., Peck, J. R., Liu, C., Kim, C. K., Tian, L., Deisseroth, K. \& Lammel, S. (2019). A Neural Circuit Mechanism for Encoding Aversive Stimuli in the Mesolimbic Dopamine System. Neuron 101, 133-151 e7.

Everitt, B. J. \& Robbins, T. W. (2005). Neural systems of reinforcement for drug addiction: from actions to habits to compulsion. Nat Neurosci 8, 1481-9.

Fitzgerald, B. J., Richardson, K. \& Wesson, D. W. (2014). Olfactory tubercle stimulation alters odor preference behavior and recruits forebrain reward and motivational centers. Front Behav Neurosci 8, 81.

Gadziola, M. A., Stetzik, L. A., Wright, K. N., Milton, A. J., Arakawa, K., Del Mar Cortijo, M. \& Wesson, D. W. (2020). A Neural System that Represents the Association of Odors with Rewarded Outcomes and Promotes Behavioral Engagement. Cell Rep 32, 107919.

Gadziola, M. A., Tylicki, K. A., Christian, D. L. \& Wesson, D. W. (2015). The olfactory tubercle encodes odor valence in behaving mice. J Neurosci 35, 4515-27.

Gerfen, C. R., Paletzki, R. \& Heintz, N. (2013). GENSAT BAC cre-recombinase driver lines to study the functional organization of cerebral cortical and basal ganglia circuits. Neuron $\mathbf{8 0}, 1368-83$.

Gerfen, C. R. \& Surmeier, D. J. (2011). Modulation of striatal projection systems by dopamine. Annu Rev Neurosci 34, 441-66.

Giovannucci, A., Friedrich, J., Gunn, P., Kalfon, J., Brown, B. L., Koay, S. A., Taxidis, J., Najafi, F., Gauthier, J. L., Zhou, P., Khakh, B. S., Tank, D. W., Chklovskii, D. B. \& Pnevmatikakis, E. A. (2019). CalmAn an open source tool for scalable calcium imaging data analysis. Elife 8.

Hagamen, T. C., Greeley, H. P., Hagamen, W. D. \& Reeves, A. G. (1977). Behavioral asymmetries following olfactory tubercle lesions in cats. Brain Behav Evol 14, 241-50.

Herz, R. S. (2016). The Role of Odor-Evoked Memory in Psychological and Physiological Health. Brain Sci 6.

Igarashi, K. M., leki, N., An, M., Yamaguchi, Y., Nagayama, S., Kobayakawa, K., Kobayakawa, R., Tanifuji, M., Sakano, H., Chen, W. R. \& Mori, K. (2012). Parallel mitral and tufted cell pathways route distinct odor information to different targets in the olfactory cortex. J Neurosci 32, 7970-85.

lino, Y., Sawada, T., Yamaguchi, K., Tajiri, M., Ishii, S., Kasai, H. \& Yagishita, S. (2020). Dopamine D2 receptors in discrimination learning and spine enlargement. Nature 579, 555-560.

Ikemoto, S. (2003). Involvement of the olfactory tubercle in cocaine reward: intracranial self-administration studies. J Neurosci 23, 9305-11.

Ikemoto, S. (2007). Dopamine reward circuitry: two projection systems from the ventral midbrain to the nucleus accumbens-olfactory tubercle complex. Brain Res Rev 56, 27-78.

Kaas, J. H. (2008). The evolution of the complex sensory and motor systems of the human brain. Brain Res Bull 75, 38490.

Kapoor, V., Provost, A. C., Agarwal, P. \& Murthy, V. N. (2016). Activation of raphe nuclei triggers rapid and distinct effects on parallel olfactory bulb output channels. Nat Neurosci 19, 271-82.

Keiflin, R. \& Janak, P. H. (2015). Dopamine Prediction Errors in Reward Learning and Addiction: From Theory to Neural Circuitry. Neuron 88, 247-63.

Koob, G. F., Riley, S. J., Smith, S. C. \& Robbins, T. W. (1978). Effects of 6-hydroxydopamine lesions of the nucleus accumbens septi and olfactory tubercle on feeding, locomotor activity, and amphetamine anorexia in the rat. J Comp Physiol Psychol 92, 917-27.

Koob, G. F. \& Volkow, N. D. (2010). Neurocircuitry of addiction. Neuropsychopharmacology 35, 217-38.

Kutlu, M. G., Zachry, J. E., Melugin, P. R., Cajigas, S. A., Chevee, M. F., Kelley, S. J., Kutlu, B., Tian, L., Siciliano, C. A. \& Calipari, E. S. (2021). Dopamine release in the nucleus accumbens core signals perceived saliency. Curr Biol.

Lovinger, D. M. (2010). Neurotransmitter roles in synaptic modulation, plasticity and learning in the dorsal striatum. Neuropharmacology 58, 951-61.

Midroit, M., Chalencon, L., Renier, N., Milton, A., Thevenet, M., Sacquet, J., Breton, M., Forest, J., Noury, N., Richard, M., Raineteau, O., Ferdenzi, C., Fournel, A., Wesson, D. W., Bensafi, M., Didier, A. \& Mandairon, N. (2021). Neural processing of the reward value of pleasant odorants. Curr Biol 31, 1592-1605 e9.

Miles, A. N. \& Berntsen, D. (2011). Odour-induced mental time travel into the past and future: do odour cues retain a unique link to our distant past? Memory 19, 930-40.

Millman, D. J. \& Murthy, V. N. (2020). Rapid Learning of Odor-Value Association in the Olfactory Striatum. J Neurosci. 
Murata, K., Kanno, M., leki, N., Mori, K. \& Yamaguchi, M. (2015). Mapping of Learned Odor-Induced Motivated Behaviors in the Mouse Olfactory Tubercle. J Neurosci 35, 10581-99.

Murata, K., Kinoshita, T., Fukazawa, Y., Kobayashi, K., Yamanaka, A., Hikida, T., Manabe, H. \& Yamaguchi, M. (2019). Opposing Roles of Dopamine Receptor D1- and D2-Expressing Neurons in the Anteromedial Olfactory Tubercle in Acquisition of Place Preference in Mice. Front Behav Neurosci 13, 50.

Nagy, A., Eordegh, G., Paroczy, Z., Markus, Z. \& Benedek, G. (2006). Multisensory integration in the basal ganglia. Eur J Neurosci 24, 917-24.

Nagy, A., Paroczy, Z., Norita, M. \& Benedek, G. (2005). Multisensory responses and receptive field properties of neurons in the substantia nigra and in the caudate nucleus. Eur J Neurosci 22, 419-24.

Nicola, S. M., Surmeier, J. \& Malenka, R. C. (2000). Dopaminergic modulation of neuronal excitability in the striatum and nucleus accumbens. Annu Rev Neurosci 23, 185-215.

Pakan, J. M., Francioni, V. \& Rochefort, N. L. (2018). Action and learning shape the activity of neuronal circuits in the visual cortex. Curr Opin Neurobiol 52, 88-97.

Petzold, G. C., Hagiwara, A. \& Murthy, V. N. (2009). Serotonergic modulation of odor input to the mammalian olfactory bulb. Nat Neurosci 12, 784-91.

Pnevmatikakis, E. A. \& Giovannucci, A. (2017). NoRMCorre: An online algorithm for piecewise rigid motion correction of calcium imaging data. J Neurosci Methods 291, 83-94.

Pointer, S. C. \& Bond, N. W. (1998). Context-dependent memory: colour versus odour. Chem Senses 23, 359-62.

Purves D, A. G., Fitzpatrick D, et al. (2001). Neuroscience: Central Projections of the Olfactory Bulb. Sinauer Associates: Sunderland (MA).

Reid, C. A., Green, J. D., Wildschut, T. \& Sedikides, C. (2015). Scent-evoked nostalgia. Memory 23, 157-66.

Reig, R. \& Silberberg, G. (2014). Multisensory integration in the mouse striatum. Neuron 83, 1200-12.

Schneider, J. (2013). Brain Structure and Its Origins. MIT Press.

Soucy, E. R., Albeanu, D. F., Fantana, A. L., Murthy, V. N. \& Meister, M. (2009). Precision and diversity in an odor map on the olfactory bulb. Nat Neurosci 12, 210-20.

Surmeier, D. J., Ding, J., Day, M., Wang, Z. \& Shen, W. (2007). D1 and D2 dopamine-receptor modulation of striatal glutamatergic signaling in striatal medium spiny neurons. Trends Neurosci 30, 228-35.

Svenningsson, P., Le Moine, C., Aubert, I., Burbaud, P., Fredholm, B. B. \& Bloch, B. (1998). Cellular distribution of adenosine A2A receptor mRNA in the primate striatum. J Comp Neurol 399, 229-40.

Svoboda, K. \& Li, N. (2018). Neural mechanisms of movement planning: motor cortex and beyond. Curr Opin Neurobiol 49, 33-41.

Tanaka, M., Kunimatsu, J., Suzuki, T. W., Kameda, M., Ohmae, S., Uematsu, A. \& Takeya, R. (2021). Roles of the Cerebellum in Motor Preparation and Prediction of Timing. Neuroscience 462, 220-234.

Varga, A. G. \& Wesson, D. W. (2013). Distributed auditory sensory input within the mouse olfactory cortex. Eur J Neurosci 37, 564-71.

Wesson, D. W. \& Wilson, D. A. (2010). Smelling sounds: olfactory-auditory sensory convergence in the olfactory tubercle. J Neurosci 30, 3013-21.

Wesson, D. W. \& Wilson, D. A. (2011). Sniffing out the contributions of the olfactory tubercle to the sense of smell: hedonics, sensory integration, and more? Neurosci Biobehav Rev 35, 655-68.

Wise, R. A. \& Koob, G. F. (2014). The development and maintenance of drug addiction. Neuropsychopharmacology 39, 254-62.

Wright, K. N. \& Wesson, D. W. (2021). The tubular striatum and nucleus accumbens distinctly represent reward-taking and reward-seeking. J Neurophysiol 125, 166-183.

Yagishita, S., Hayashi-Takagi, A., Ellis-Davies, G. C., Urakubo, H., Ishii, S. \& Kasai, H. (2014). A critical time window for dopamine actions on the structural plasticity of dendritic spines. Science 345, 1616-20.

Zhang, Z., Liu, Q., Wen, P., Zhang, J., Rao, X., Zhou, Z., Zhang, H., He, X., Li, J., Zhou, Z., Xu, X., Zhang, X., Luo, R., Lv, G., Li, H., Cao, P., Wang, L. \& Xu, F. (2017). Activation of the dopaminergic pathway from VTA to the medial olfactory tubercle generates odor-preference and reward. Elife 6. 
bioRxiv preprint doi: https://doi.org/10.1101/2021.11.01.466363; this version posted November 2, 2021. The copyright holder for this preprint (which was not certified by peer review) is the author/funder, who has granted bioRxiv a license to display the preprint in perpetuity. It is made available under aCC-BY-NC-ND 4.0 International license.

A

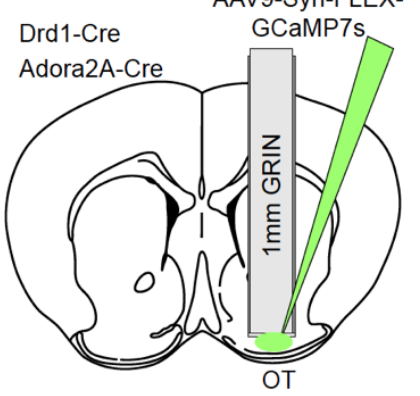

E

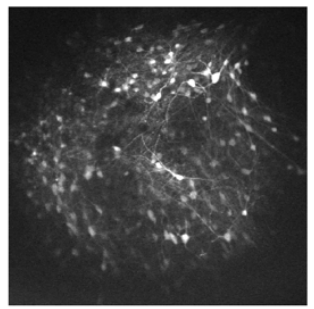

F

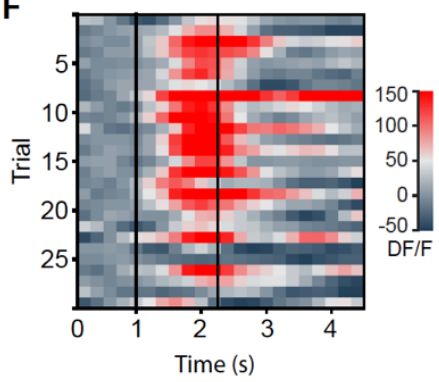

B

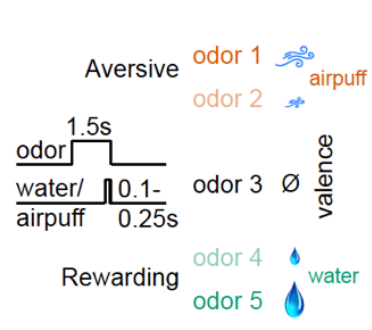

G
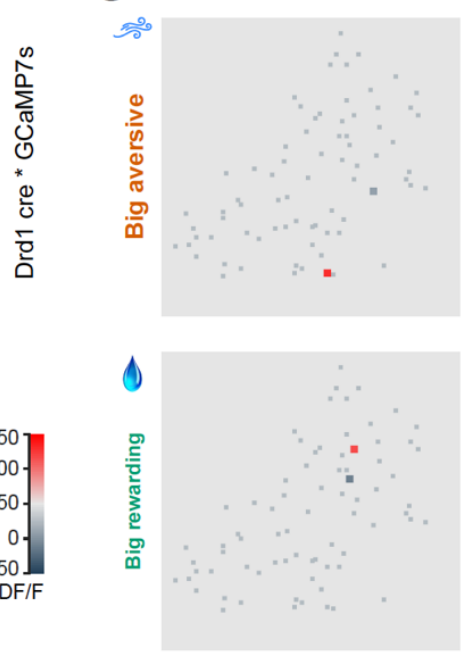

day 0 , no odors
C

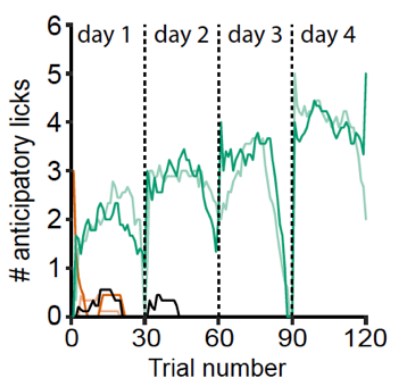

D
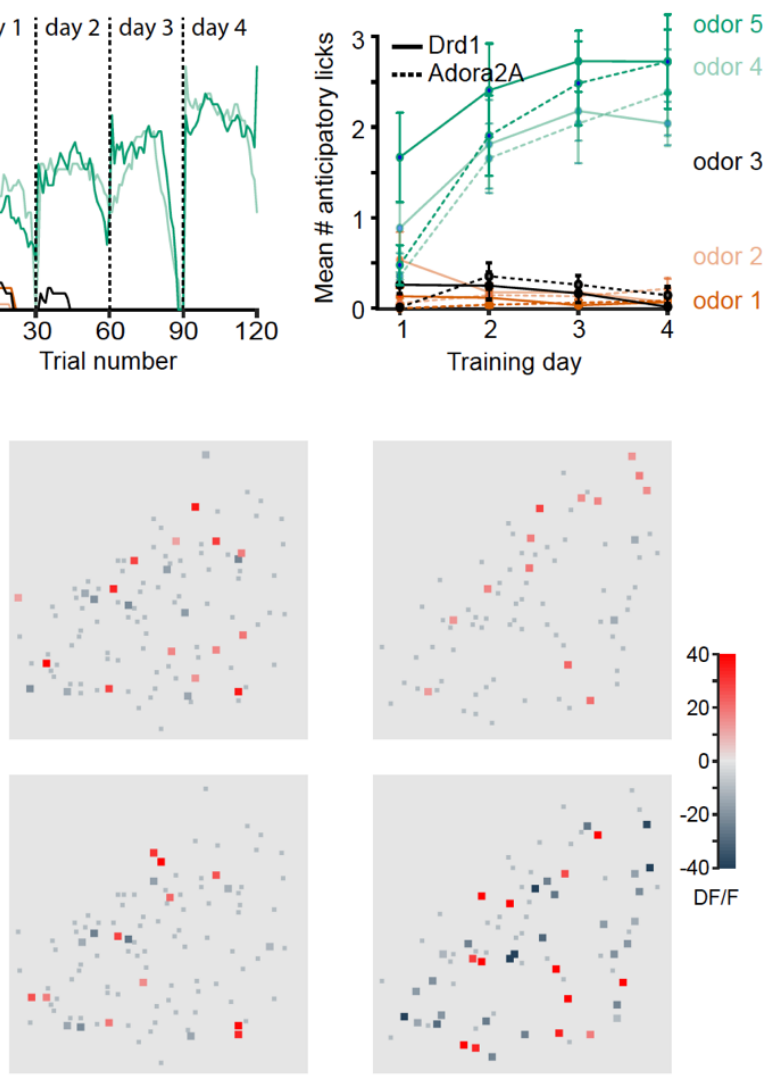

day1

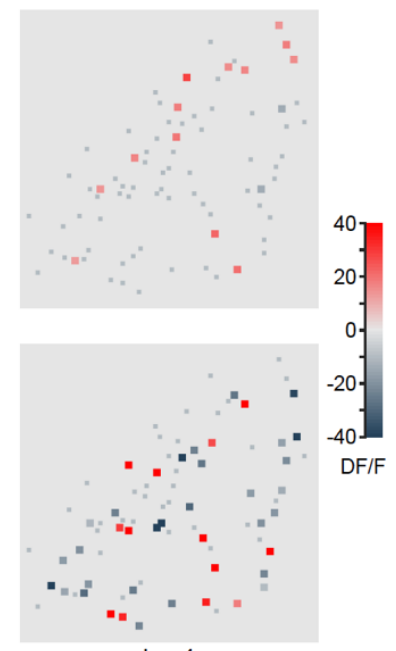

day 4

Figure 1. Two-photon calcium imaging of D1 and D2 type neurons in the OT during odor-outcome association learning. (A) Cannula and GRIN lens implantation targeting the OT in Drd1-Cre and Adora2A-Cre mice with AAV9-Syn-FLEX-GCaMP7s virus injection in the OT. (B) Odor-outcome task structure, odors 1-2 are paired with aversive airpuffs and odors 4-5 are paired with rewarding water drops in headfixed water restricted mice. Odor-outcome assignments are counterbalanced across mice. (C) Number of anticipatory licks in an example mouse in a 1s period after odor onset and prior to water or airpuff delivery. Each training day has 30 trials of each of the five odors. (D) Mean number of anticipatory licks across four days of training in implanted Drd1-Cre mice $(n=6$, solid) and Adora2A-Cre mice ( $n=6$, dashed). (E) Field of view of GCaMP7s expressing neurons in a Drd1-Cre mouse. (F) Example imaged neuron with activity in individual odor 5 trials in a single session. Dashed lines indicate odor onset and water onset. (G) Neuronal activity in field of view of a Drd1-Cre mouse in big airpuff and big water drop trials across days of training. Small gray dots indicate non-significantly responsive neurons. Day 0 indicates pre-training day in which no odors are presented, only water drops and airpuffs. Activity is shown in the 1 s period prior to outcome delivery, after odor onset in days 1 and 4. 
bioRxiv preprint doi: https://doi.org/10.1101/2021.11.01.466363; this version posted November 2, 2021. The copyright holder for this preprint (which was not certified by peer review) is the author/funder, who has granted bioRxiv a license to display the preprint in perpetuity. It is made available under aCC-BY-NC-ND 4.0 International license.

A
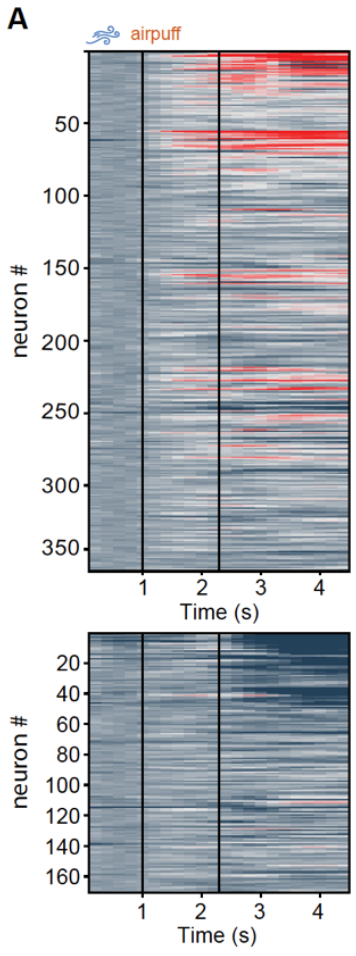

B

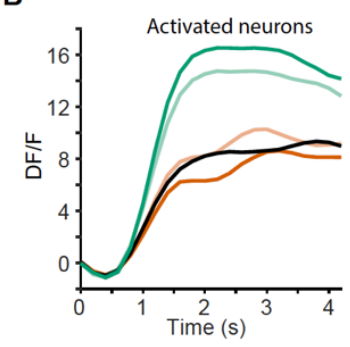

C

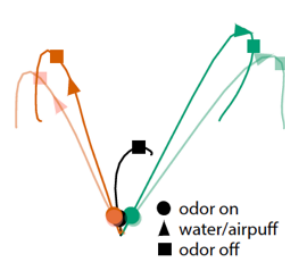

D
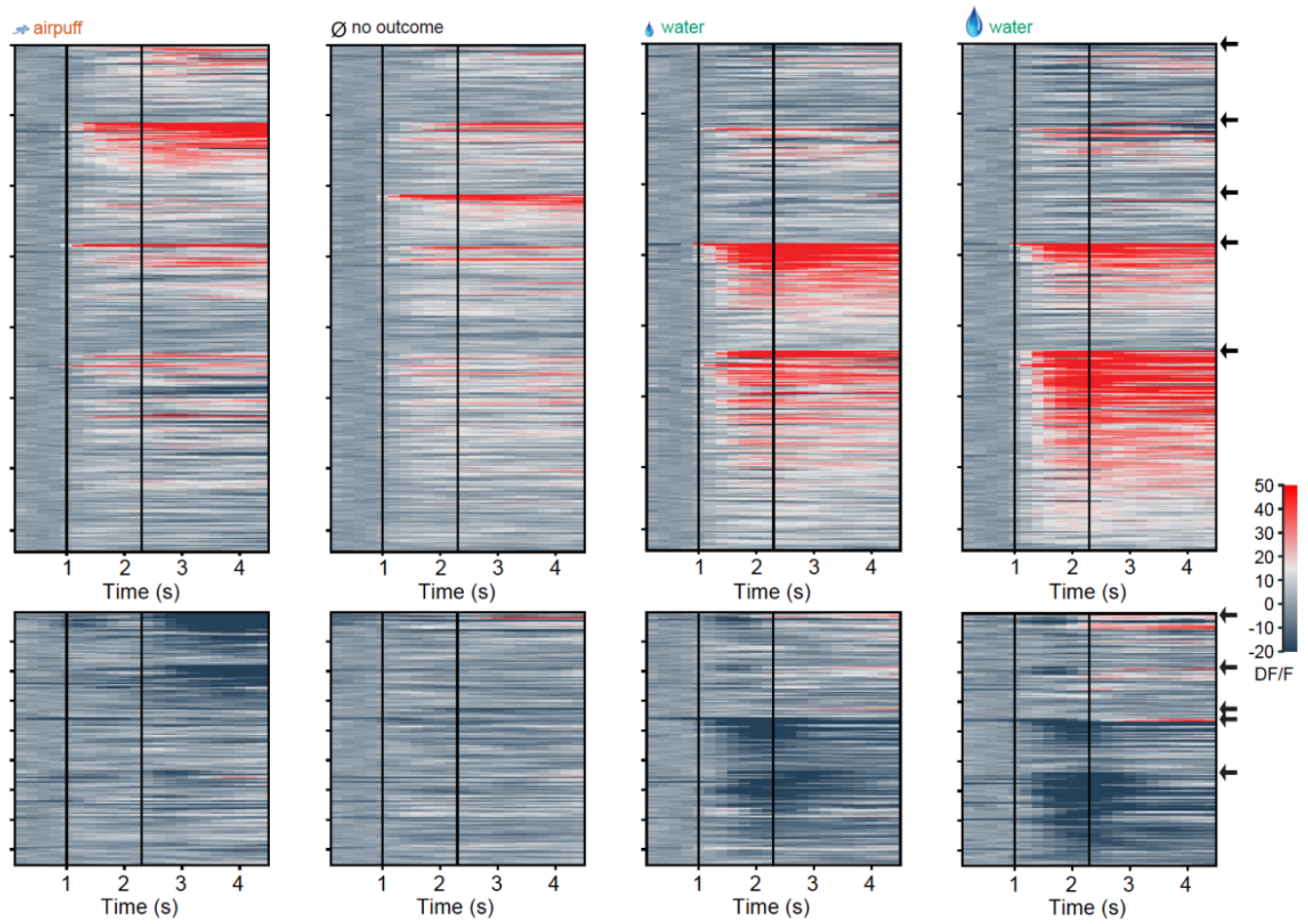

E
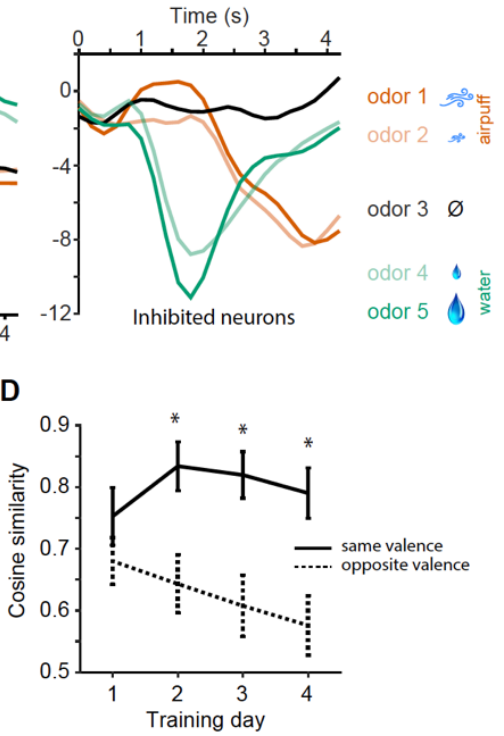
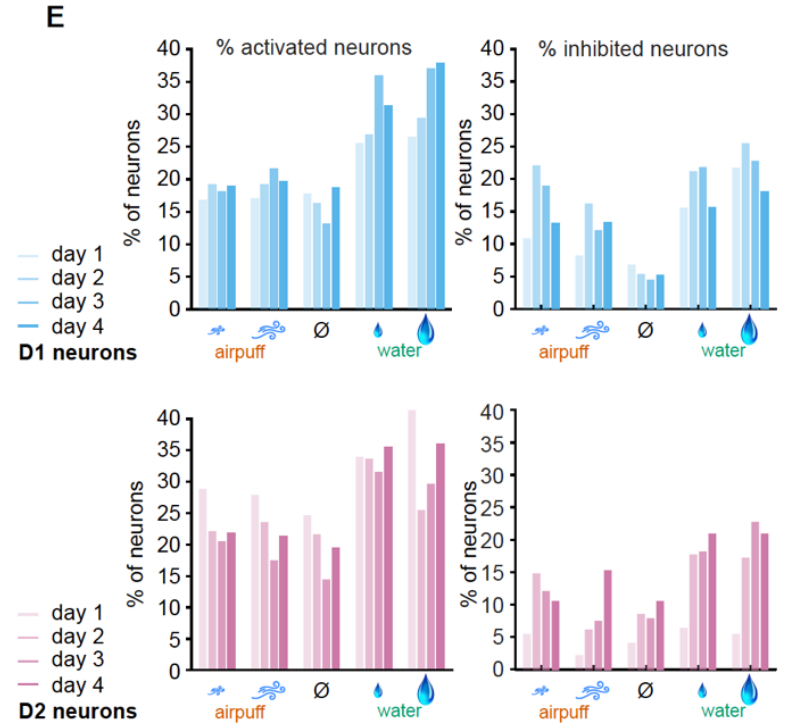

Figure 2. D1 type neurons in the OT respond most strongly to rewarded odors and respond similarly to odors of similar outcomes.

(A) Activity of all activated (top) and inhibited (bottom) neurons from six Drd1-Cre mice in five trial types on day 4 of training. Vertical black lines indicate odor onset and outcome delivery time. Neurons are grouped by preferred stimulus, arrows on right indicate boundaries between groups. Neuronal activity in the two aversive trial types (columns 1-2) is similar and neuronal activity in the two rewarding trial types (columns 4-5) is similar. (B) Mean population activity of all activated and inhibited D1 neurons in five trial types. Odor onset at 1s and outcome onset at 2.3s. (C) 3-D D1 neural population trajectories in five trial types. (D) Cosine similarity between groups of neurons responding to odor pairs of same valence or opposite valence (5 neuronal subgroups as in A with pairwise comparisons, ${ }^{*} p<0.05$ rank-sum test) (E) Proportions of significantly activated and inhibited D1 and D2 neurons on days 1-4 of training (day 4: $n=529$ D1 neurons, $\mathrm{n}=338 \mathrm{D} 2$ neurons). 
bioRxiv preprint doi: https://doi.org/10.1101/2021.11.01.466363; this version posted November 2, 2021. The copyright holder for this preprint (which was not certified by peer review) is the author/funder, who has granted bioRxiv a license to display the preprint in perpetuity. It is made available under aCC-BY-NC-ND 4.0 International license.

A

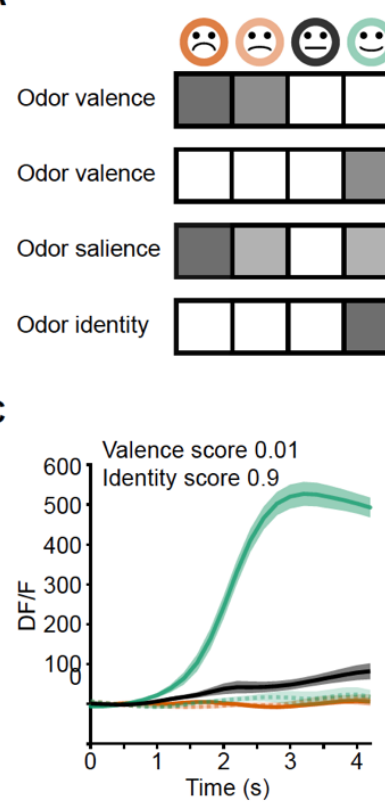

D

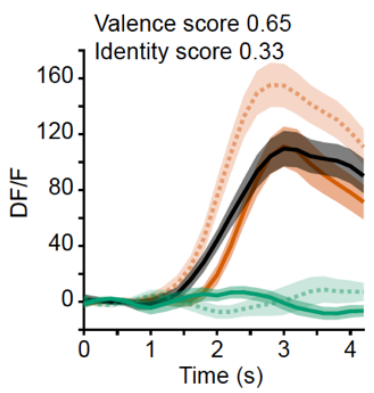

E

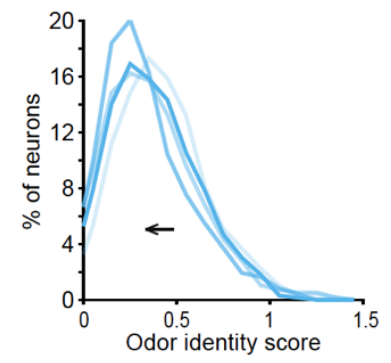

$\mathbf{F}$

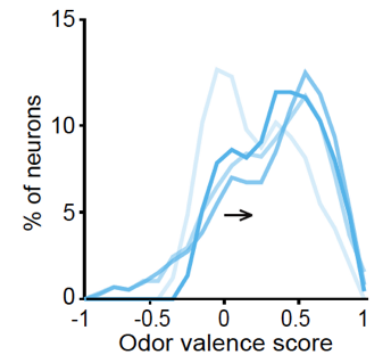

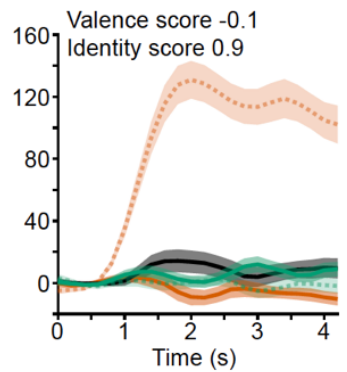

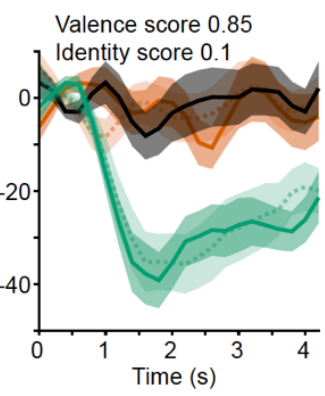

Valence score 0.76 200 Identity score 0.15
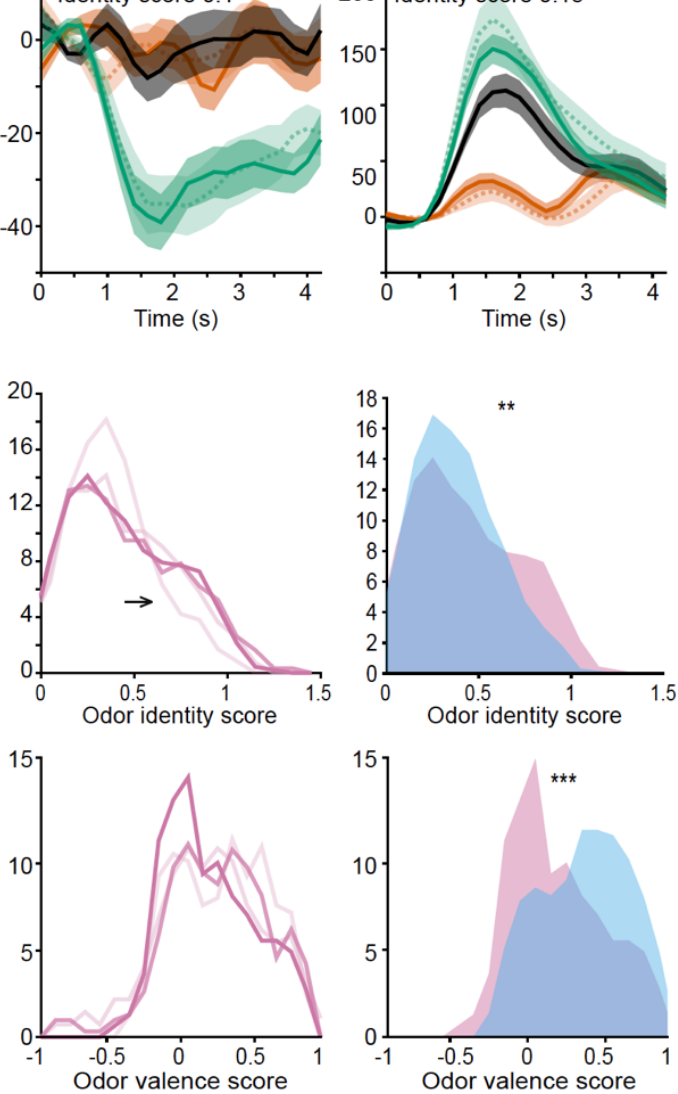

B

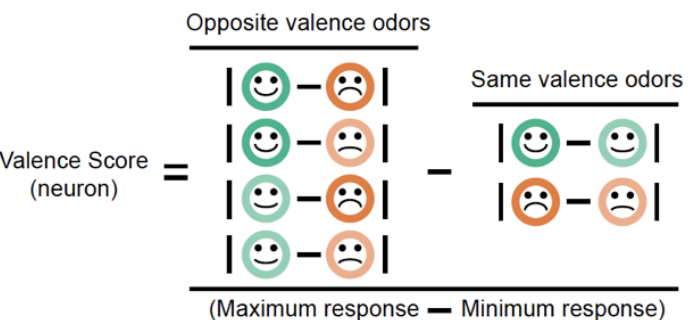

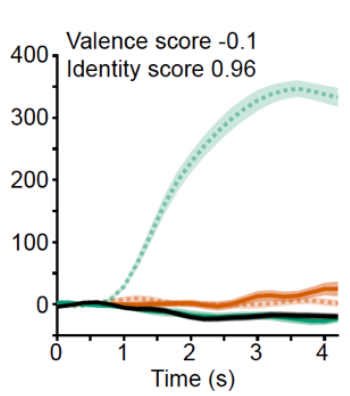

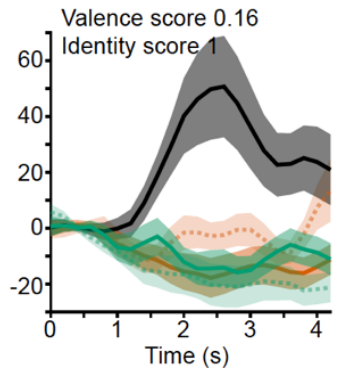

Valence score 0.86 ${ }^{120}$ ] Identity score 0.08
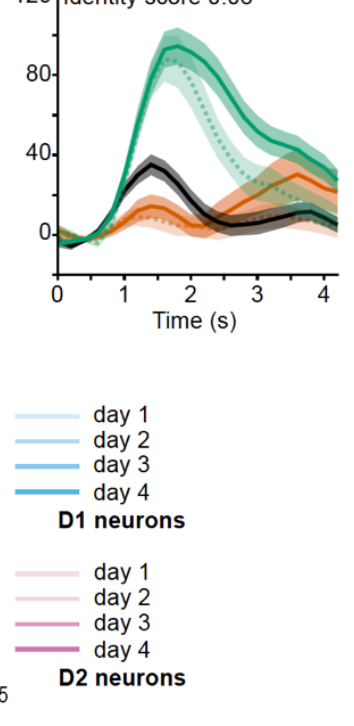

Day 4 neurons

$\mathrm{D} 1(\mathrm{n}=221)$

D2 $(n=156)$

Figure 3. Odor valence and identity coding in individual D1 and D2 OT neurons develops with learning. (A) Hypothetical responses to the five task odors in idealized odor valence coding neurons, salience coding neurons, or odor identity coding neurons. (B) Calculation of valence scores for individual neurons by comparison of responses to odors of opposite valence to odors of similar valence. (C) Examples of four individual neurons with high odor identity coding scores and low valence coding scores. (D) Examples of four individual neurons with high valence coding scores and low identity coding scores. (E) Distributions of odor identity coding scores in D1 (blue, left) and D2 (pink, middle) neurons across four days of training. D1 neuron identity scores decrease and D2 neuron identity coding scores increase with training days. Right, day 4 distributions of identity scores of $D 1$ and $D 2$ neurons ( $* * p<0.001$, rank sum test). (F) Distributions of odor valence coding scores in D1 (blue, left) and D2 (pink, middle) neurons across four days of training. D1 neuron valence scores increase with training days. Right, day 4 distributions of valence scores of D1 and D2 neurons (*** $p<0.000001$, rank sum test). 
bioRxiv preprint doi: https://doi.org/10.1101/2021.11.01.466363; this version posted November 2, 2021. The copyright holder for this preprint (which was not certified by peer review) is the author/funder, who has granted bioRxiv a license to display the preprint in perpetuity. It is made available under aCC-BY-NC-ND 4.0 International license.

A

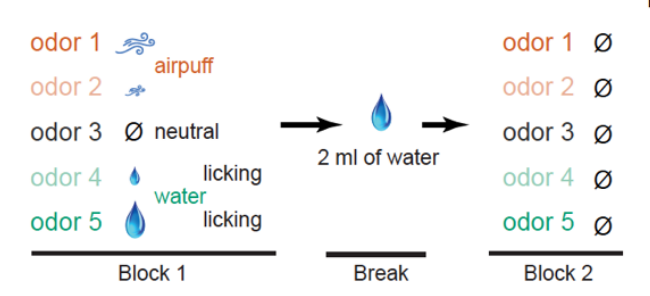

C
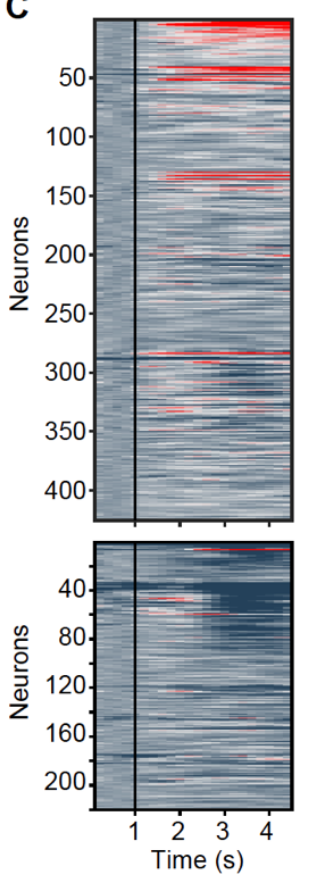

D

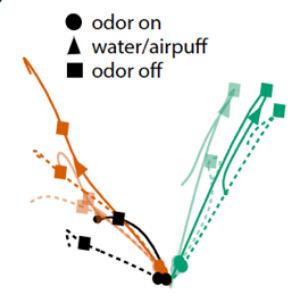

E
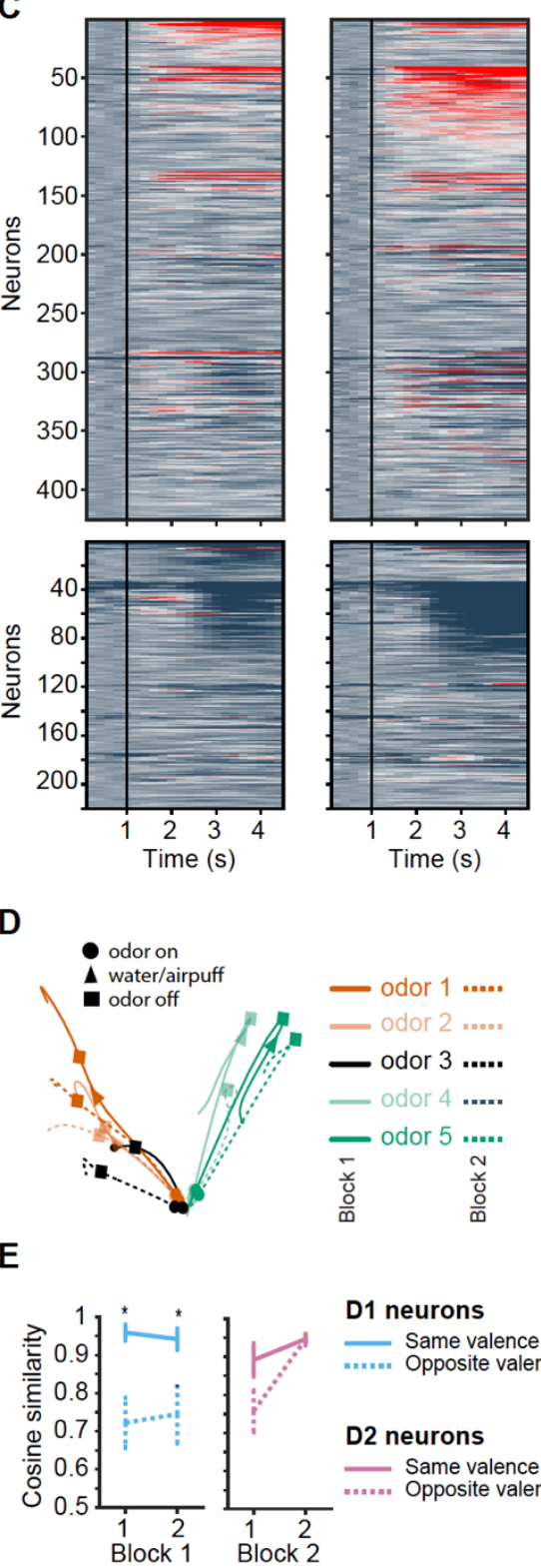

F

G

D1 neurons
B

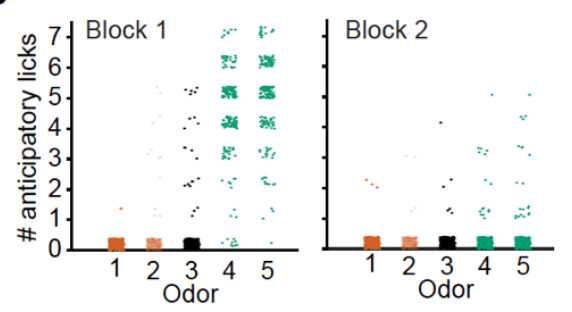

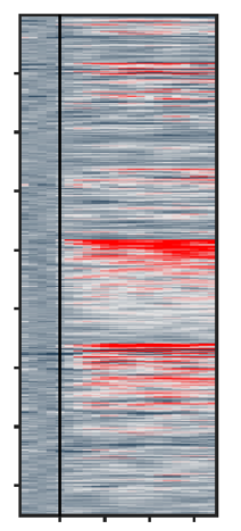
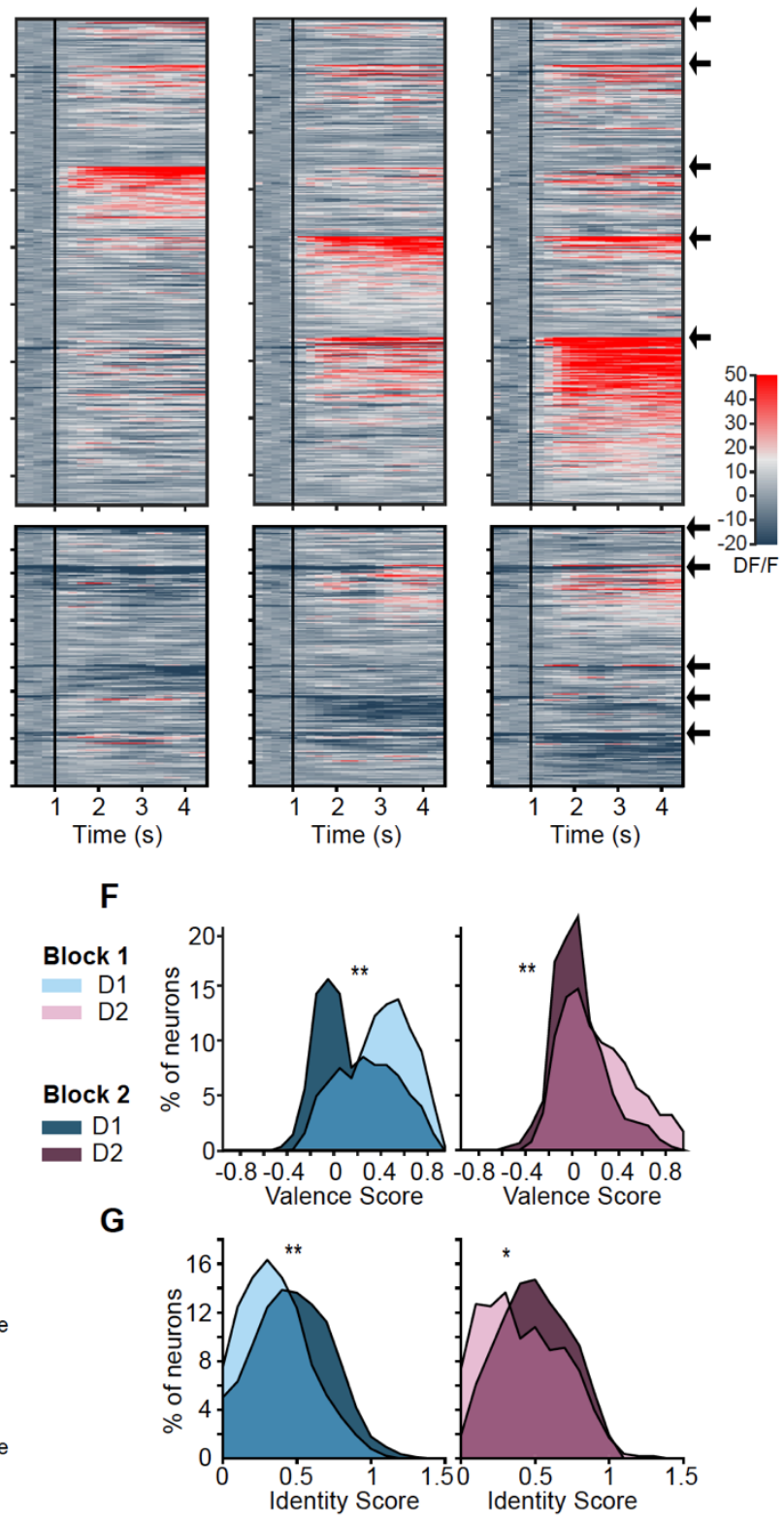

Figure 4. D1 neuronal valence coding is robustly preserved in the absence of licking response and absence of outcomes. (A) Probe session structure. In block 2 mice are sated with water, rarely exhibiting licking, and all outcomes are omitted. (B) Number of anticipatory licks in response to five odor types in blocks 1 and 2 ( $n=12$ mice, 16 trials each odor type in each block). Rare trials with non-zero anticipatory licks in block 2 were omitted from following neuronal analysis. (C) Activity of activated (top) and inhibited (bottom) D1 neurons in response to five odor types in block 2. Neurons are grouped by preferred stimulus, arrows on right indicate boundaries between groups. Black vertical lines indicate odor onset. No outcome was delivered. (D) 3-D D1 neuronal population trajectories in blocks 1 (solid lines) and 2 (dashed lines) in five trial types. (E) Cosine similarity between D1 and D2 neuronal activity averages in blocks 1 and 2 for same valence and opposite valence odors ( 5 neuronal subgroups as in $\mathrm{C}$ with pairwise comparisons, ${ }^{*} \mathrm{p}<0.05$ rank-sum test). (F) Distributions of D1 (left) and D2 (right) neuron valence scores in blocks 1 and 2 ( $n=294$ D1 and 177 D2 neurons, $* * p<0.0001$, paired t-test). (G) Same for identity scores. 
bioRxiv preprint doi: https://doi.org/10.1101/2021.11.01.466363; this version posted November 2, 2021. The copyright holder for this preprint (which was not certified by peer review) is the author/funder, who has granted bioRxiv a license to display the preprint in perpetuity. It is made available under aCC-BY-NC-ND 4.0 International license.

A

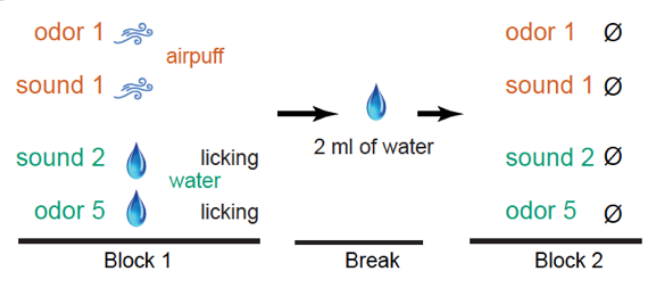

B

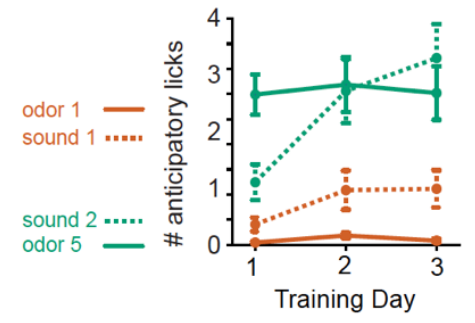

C
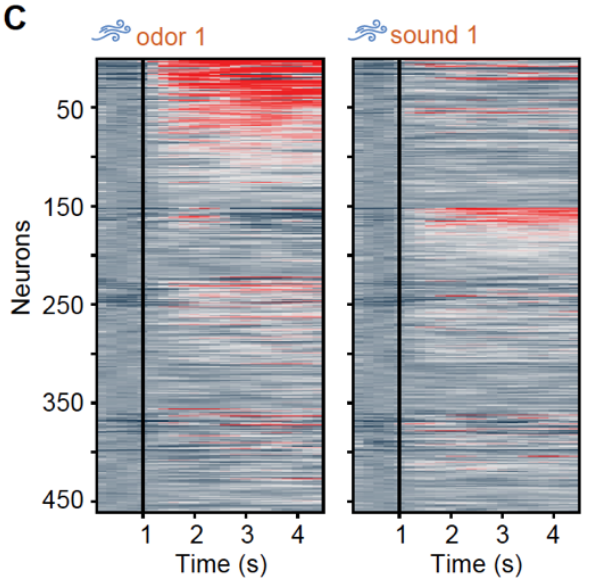

odor 5
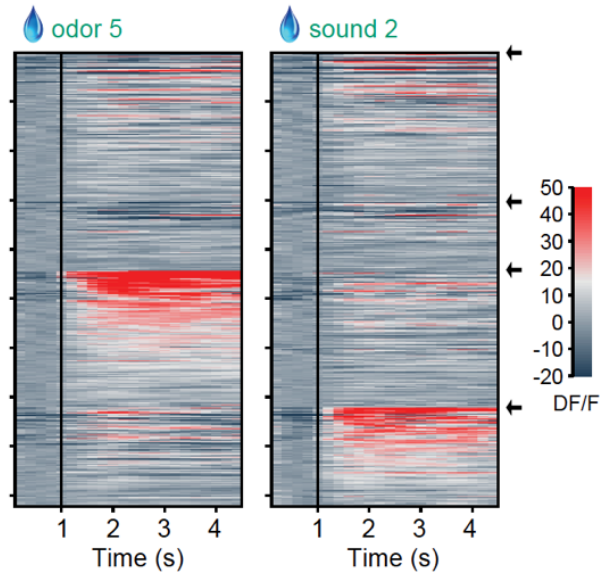

D

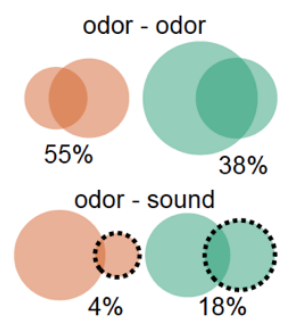

E

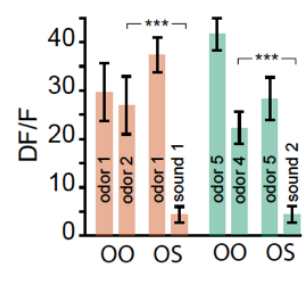

H
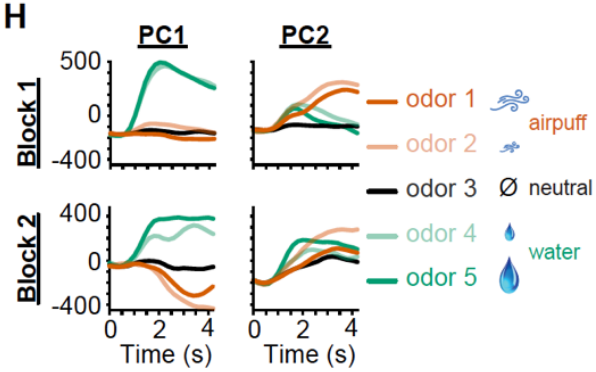

F

G

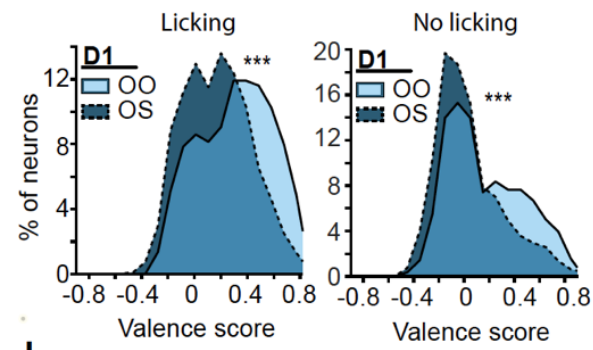

I

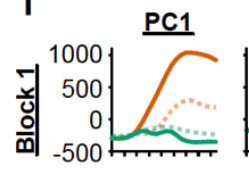

PC2

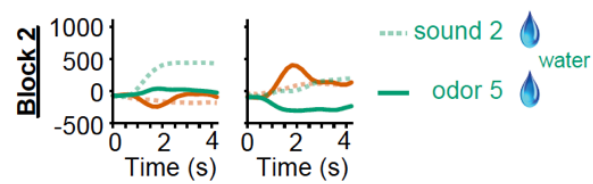

Figure 5. Odors and sound tones associated with identical aversive and rewarding outcomes activate different D1 neuronal subpopulations in the OT. (A) Odor-sound association task structure. Three days of odor-sound training beginning at the end of the prior five-odor task training are conducted. Odors 1 and 5 associated with the strongest aversive and rewarding outcomes from previously learned five-odor task are preserved and two sound tones $(5 \mathrm{kHz}$ and $12 \mathrm{kHz})$ are introduced with matching outcomes. Sound tone - outcome assignments are counterbalanced across mice. On day 4 , a probe session is conducted as previously in which mice are sated prior to the $2^{\text {nd }}$ block. In the $2^{\text {nd }}$ block mice do not exhibit licking and all outcomes are omitted. (B) Anticipatory licking of mice across three training days. By day 2, mice exhibit similar levels of anticipatory licking in response to the rewarded sound tone as to the rewarded odor $(n=10$ mice). (C) D1 neuronal population activity in block 2 of day 4, in response to the learned odors and sound tones, and in the absence of licking, airpuffs, or water delivery. Neurons are grouped by preferred stimulus, arrows on right indicate boundaries between groups. Unlike in Figure 4C, distinct sets of D1 neurons are activated in response to odors and sound tones associated with identical outcomes. (D) Overlap in neurons responding to stimuli predicting similar aversive (orange) and rewarding (green) outcomes in the sated condition in the odorodor task (top) and odor-sound task (bottom). (E) Orange, mean activity of odor 1 activated neurons to the corresponding matched valence odor stimulus in Block 2 of the odor-odor (OO) task and matched valence sound stimulus in Block 2 of the odor-sound (OS) task ( $n=50$ and 101 neurons). Green, same for odor 5 responsive neurons ( $n=100$ and 134), (F) Distributions of valence scores of D1 neurons in the odorodor task and odor-sound task in the full task condition with licking and outcomes, (G) Same for stimulus only condition in block 2, (H) Principal components of D1 neuronal population activity in blocks 1 and 2 in odor-odor task, (I) same for odor-sound task. 
bioRxiv preprint doi: https://doi.org/10.1101/2021.11.01.466363; this version posted November 2, 2021. The copyright holder for this preprint (which was not certified by peer review) is the author/funder, who has granted bioRxiv a license to display the preprint in perpetuity. It is made available under aCC-BY-NC-ND 4.0 International license.

A
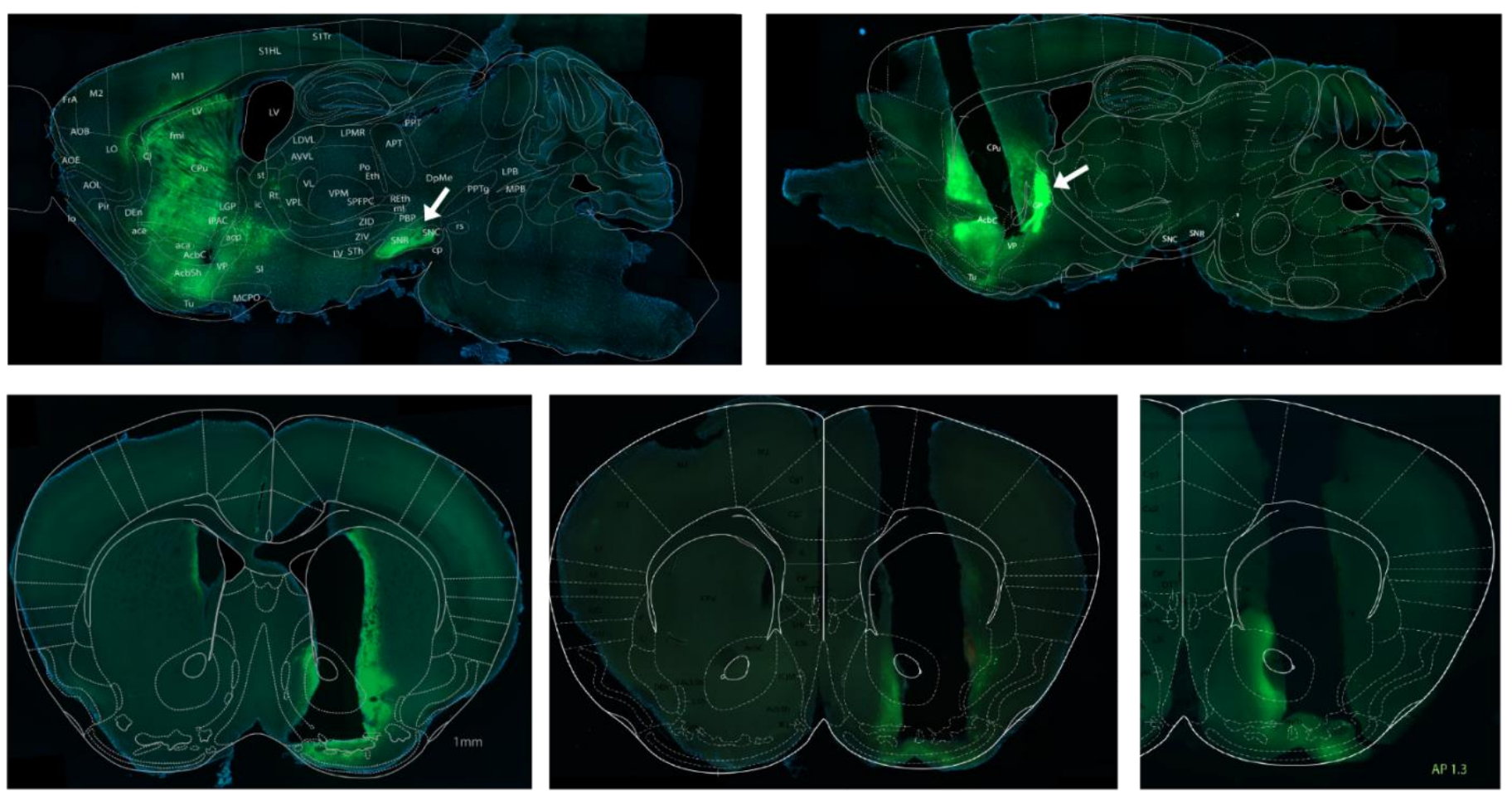

C

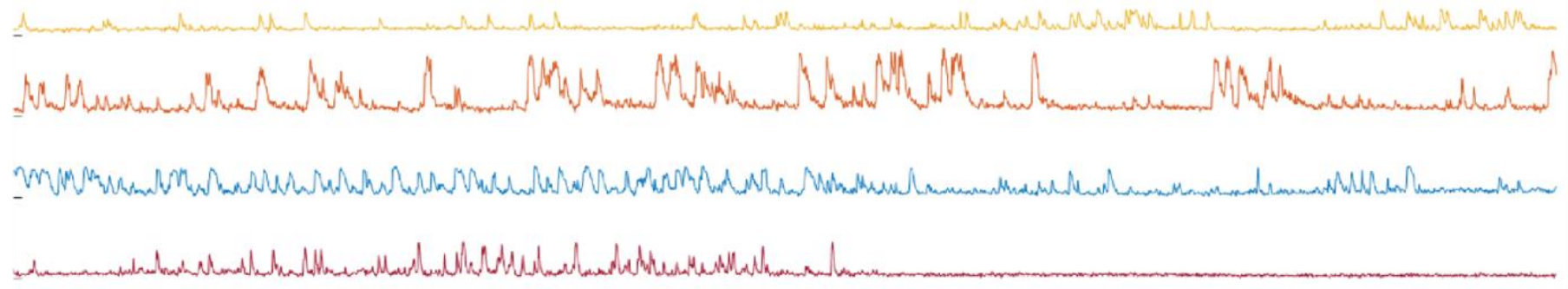

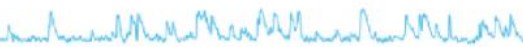

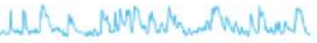

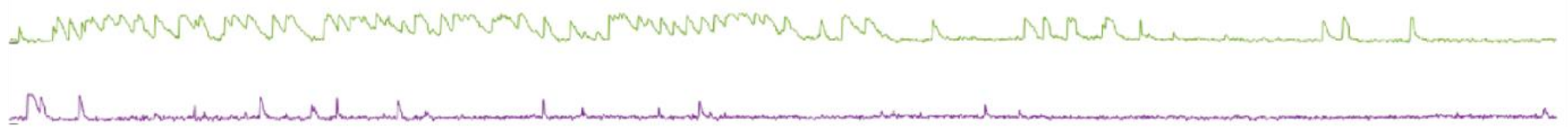

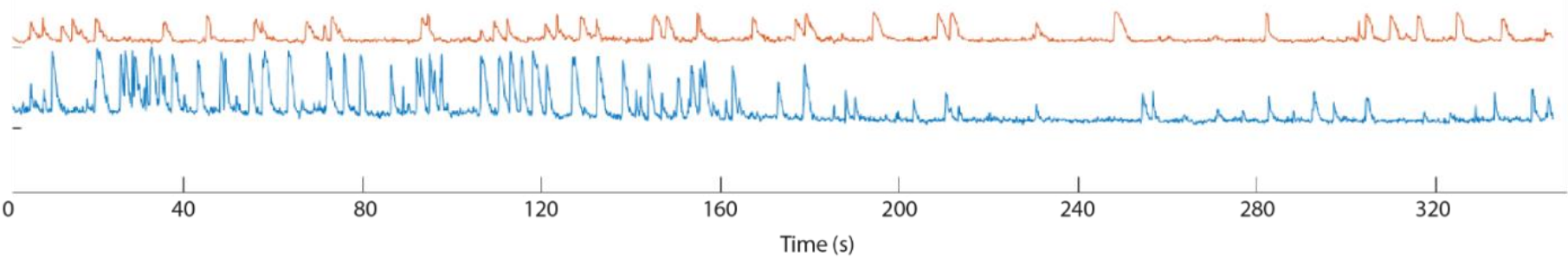

Supplementary Figure 1. Two-photon imaging of calcium activity in Drd1-Cre and Adora2A-Cre transgenic mice. (A) Left, in Drd1Cre mice injected with AAV9-Syn-FLEX-GCaMP7s virus, GCaMP expressing axons are found in the Substantia Nigra pars reticulata (arrow) as part of the striatal direct output pathway. Right, in Adora2A-Cre mice injected with AAV9-Syn-FLEX-GCaMP7s virus, GCaMP expressing axons are found in the Globus Pallidus (arrow) as part of the striatal indirect output pathway. Cannula and virus injection not targeting OT in examples. (B) $1 \mathrm{~mm}$ cannula targeting the OT. (C) Calcium transients recorded in isolated D2 neurons. 
bioRxiv preprint doi: https://doi.org/10.1101/2021.11.01.466363; this version posted November 2, 2021. The copyright holder for this preprint (which was not certified by peer review) is the author/funder, who has granted bioRxiv a license to display the preprint in perpetuity. It is made available under aCC-BY-NC-ND 4.0 International license.

A
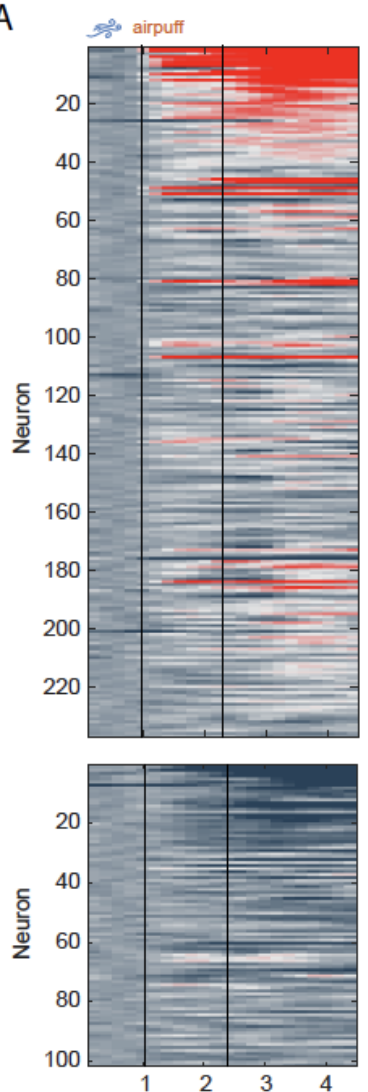

B

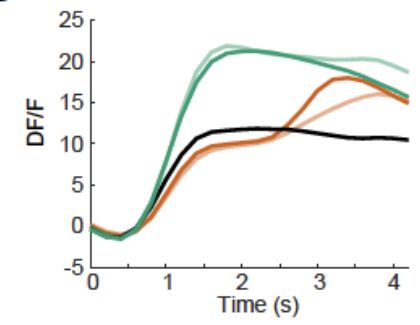

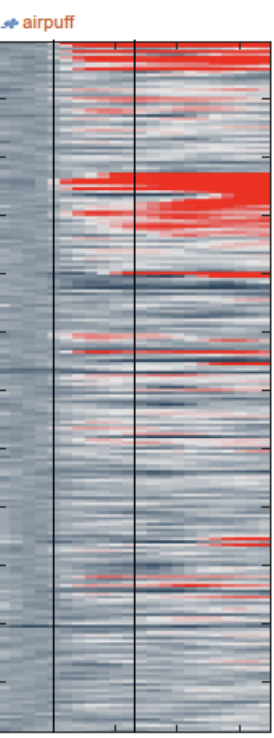
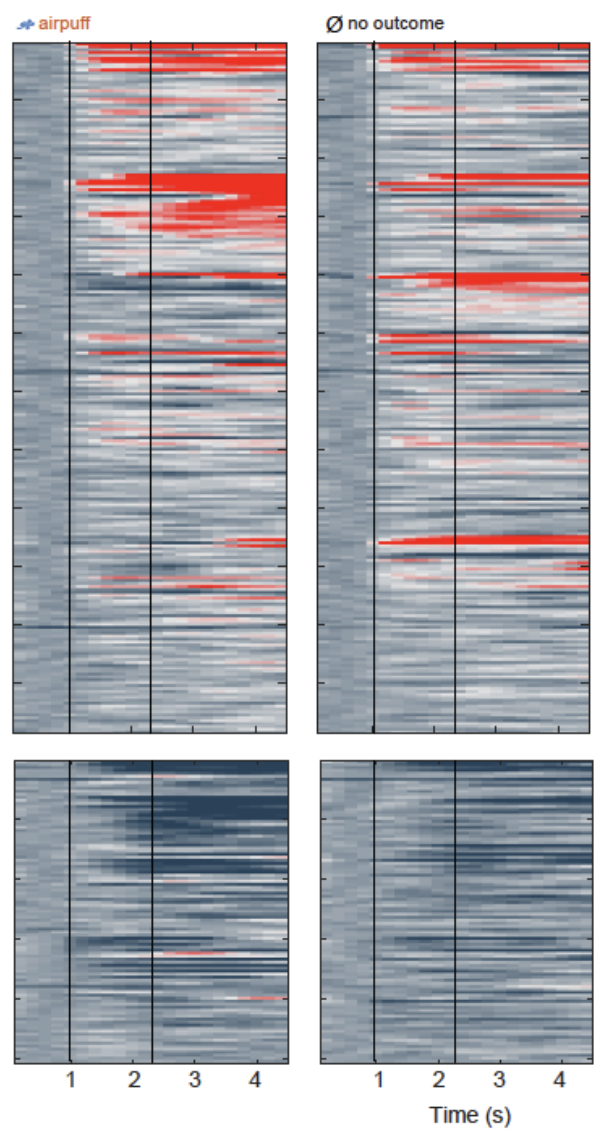

s water

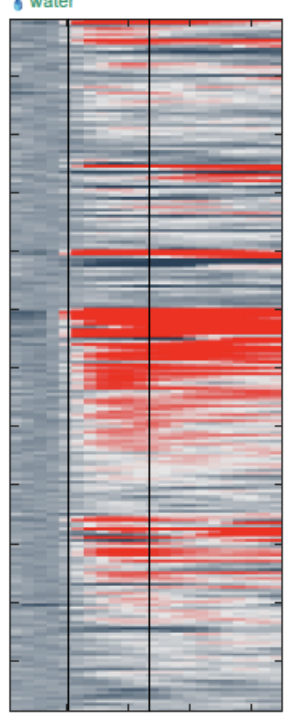

water
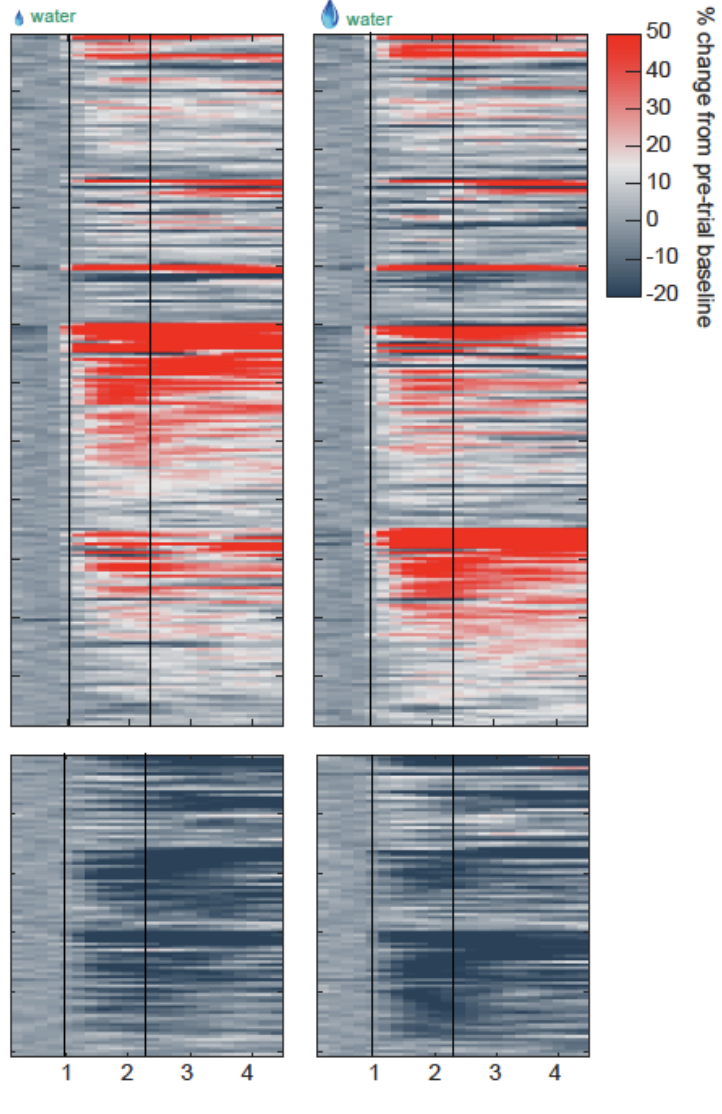
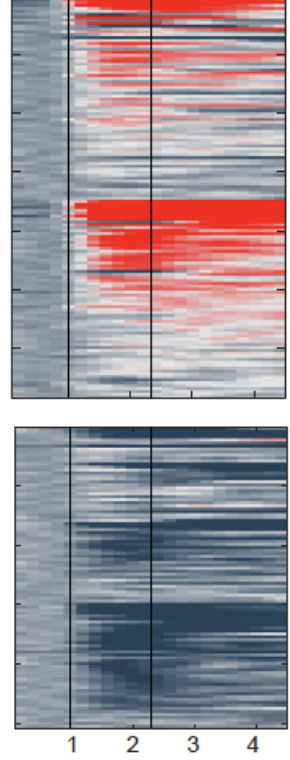

C

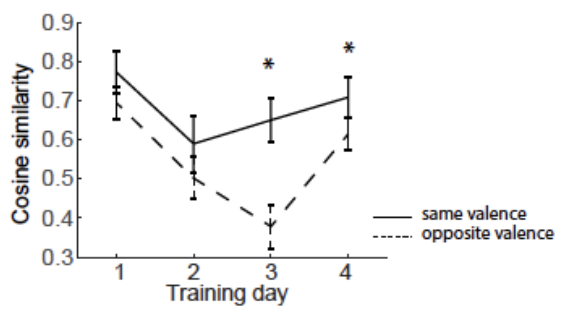

Supplementary Figure 2. D2 neuronal activity in odor-outcome association task. (A) Activity of all activated (top) and inhibited (bottom) D2-type neurons in five trial types on day 4 of training. Neurons are grouped by preferred stimulus. Vertical black lines indicate odor onset and outcome delivery time. (B) Mean population activity of all activated and inhibited D2 neurons in five trial types. Odor onset at $1 \mathrm{~s}$ and outcome onset at 1.3s. (C) Cosine similarity between groups of neurons responding to odor pairs of same valence or opposite valence ( 5 neuronal subgroups as in A, with pairwise comparisons, * $p<0.05$ rank-sum test) 
bioRxiv preprint doi: https://doi.org/10.1101/2021.11.01.466363; this version posted November 2, 2021. The copyright holder for this preprint (which was not certified by peer review) is the author/funder, who has granted bioRxiv a license to display the preprint in perpetuity. It is made available under aCC-BY-NC-ND 4.0 International license.
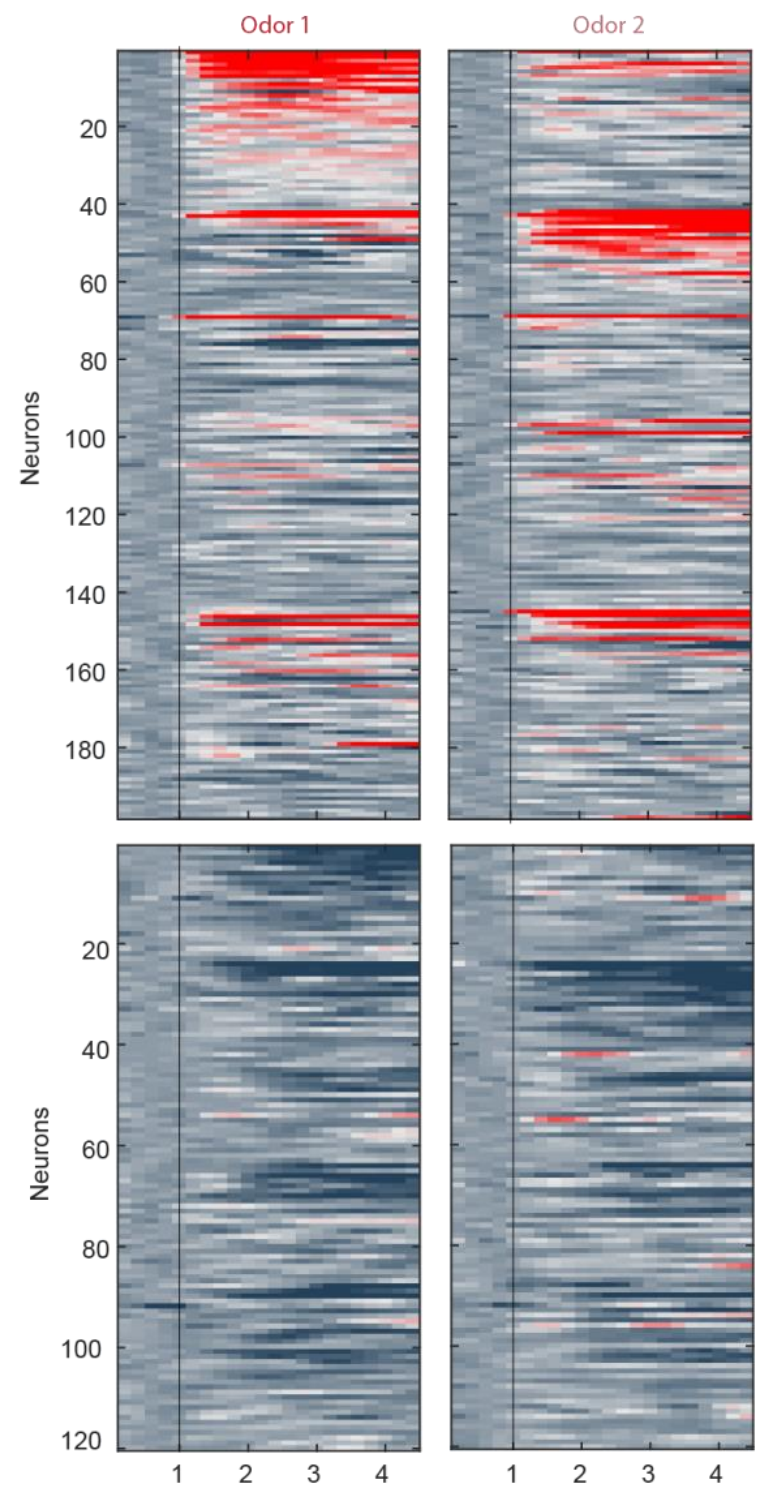

Odor 2

Odor 3
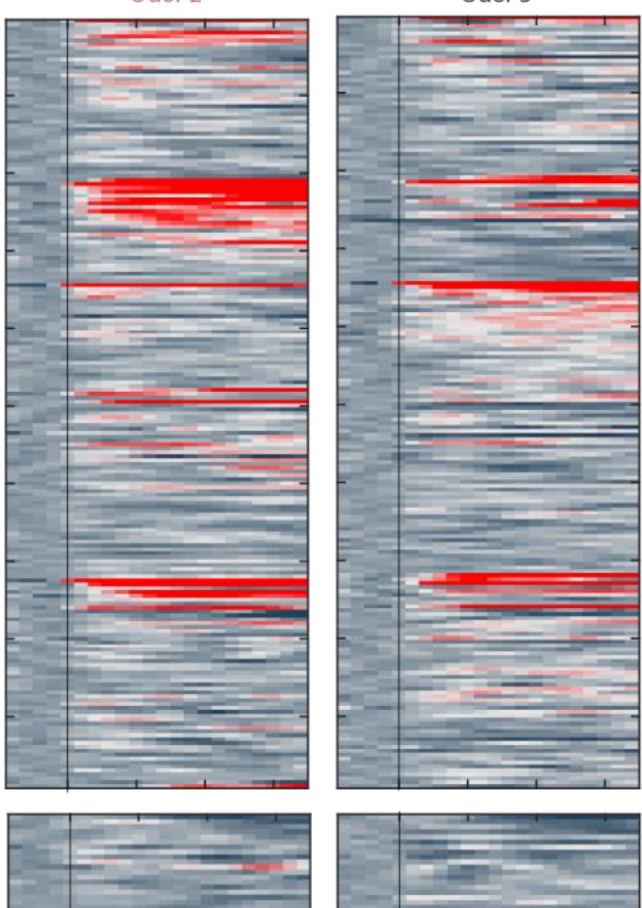
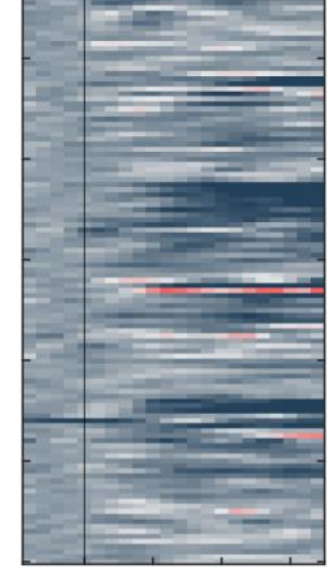

1

Time (s)

Odor 4
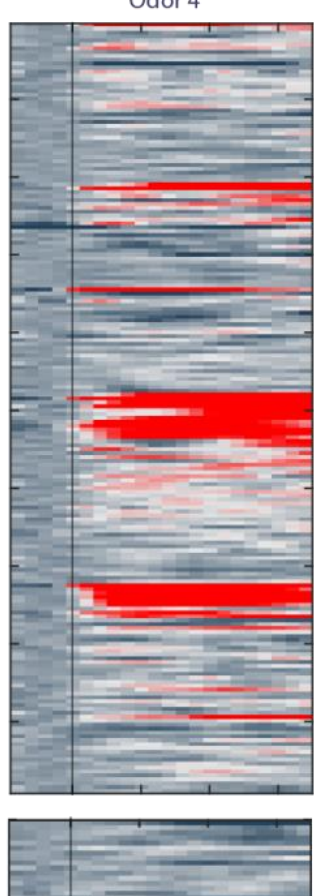

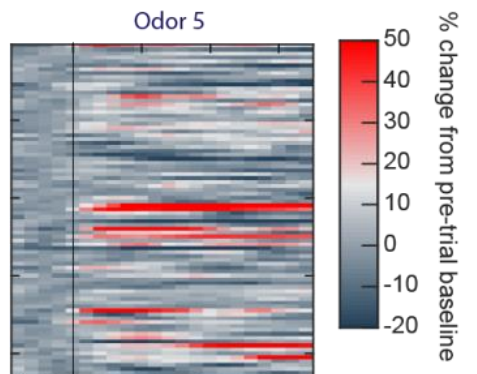

Supplementary Figure 3. D2 neuronal activity in sated Block 2 with no licking and no water/airpuff outcomes. Activity of all activated (top) and inhibited (bottom) D2 neurons in response to five odor types in Block 2. Neurons are grouped by preferred stimulus. Black vertical lines indicate odor onset. No outcome was delivered and only trials with zero licks were included in analysis. 
bioRxiv preprint doi: https://doi.org/10.1101/2021.11.01.466363; this version posted November 2, 2021. The copyright holder for this preprint (which was not certified by peer review) is the author/funder, who has granted bioRxiv a license to display the preprint in perpetuity. It is made available under aCC-BY-NC-ND 4.0 International license.
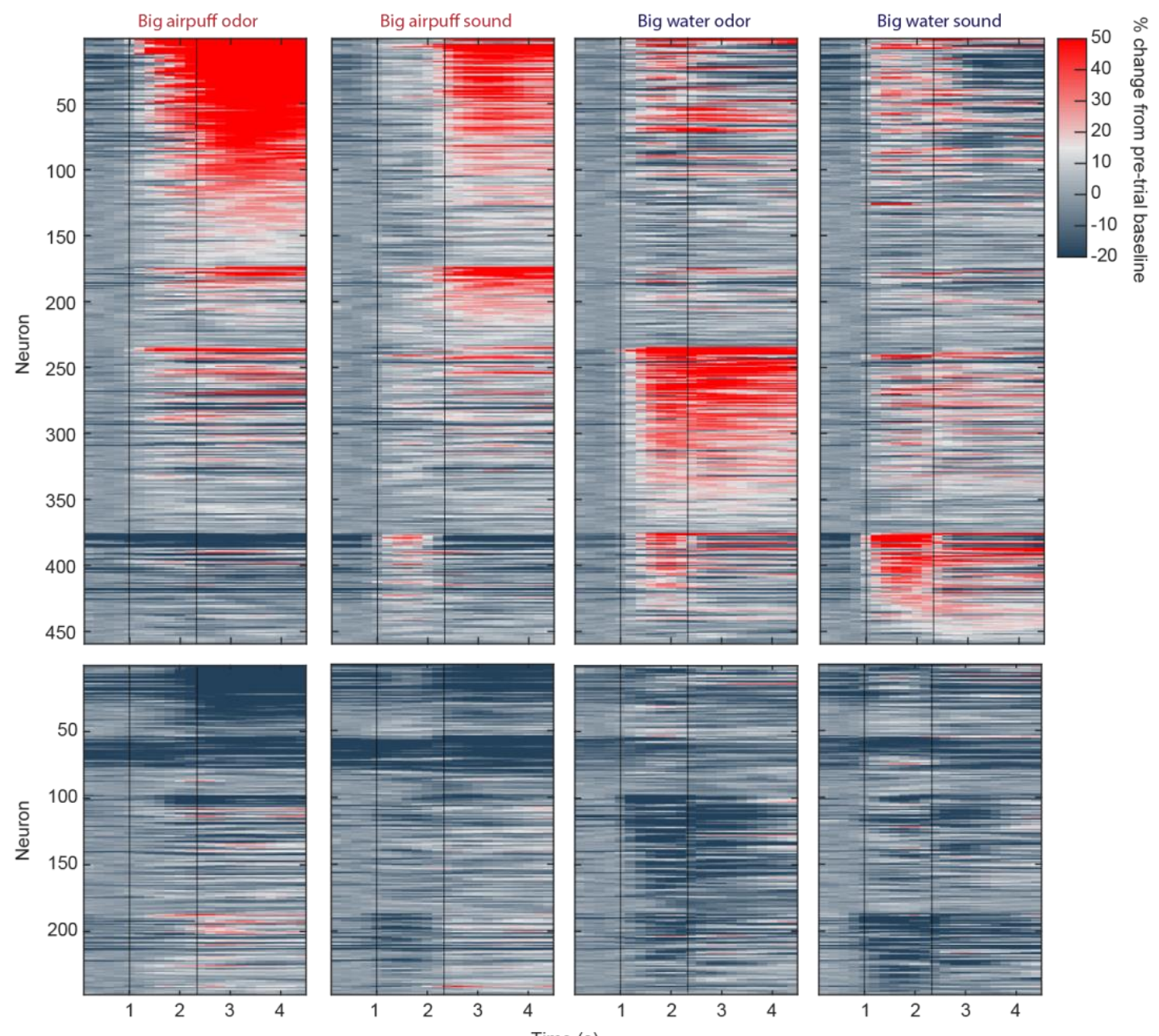

Supplementary Figure 4. D1 neuronal activity in full odor sound task, including licking and water/airpuff outcomes. Activity of all activated (top) and inhibited (bottom) D1 neurons in four trial types on day 3 of training in the odor-sound task. Neurons are grouped by preferred stimulus. Vertical black lines indicate odor onset and outcome delivery time. 
bioRxiv preprint doi: https://doi.org/10.1101/2021.11.01.466363; this version posted November 2, 2021. The copyright holder for this preprint (which was not certified by peer review) is the author/funder, who has granted bioRxiv a license to display the preprint in perpetuity. It is made available under aCC-BY-NC-ND 4.0 International license.

A
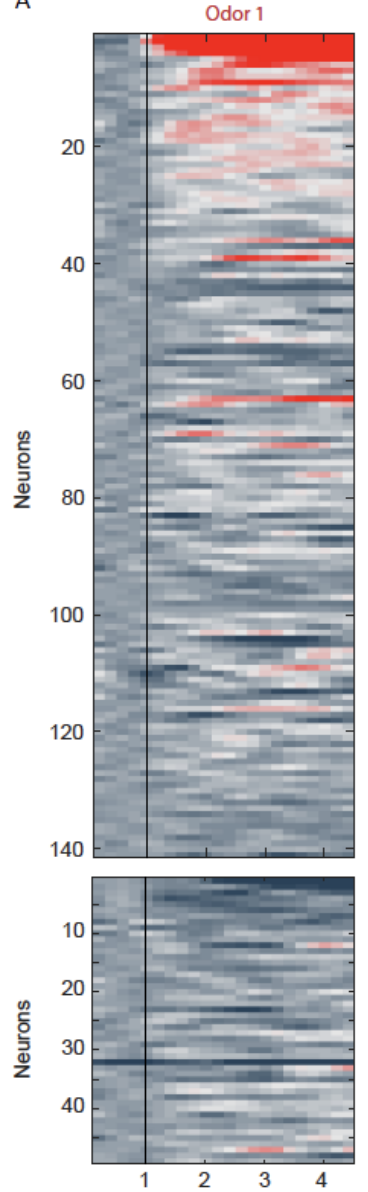

B

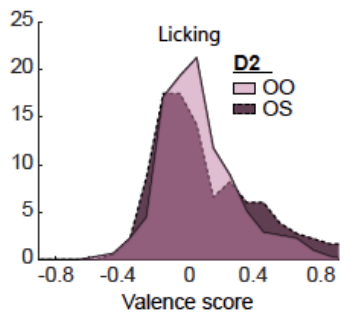

Sound 1
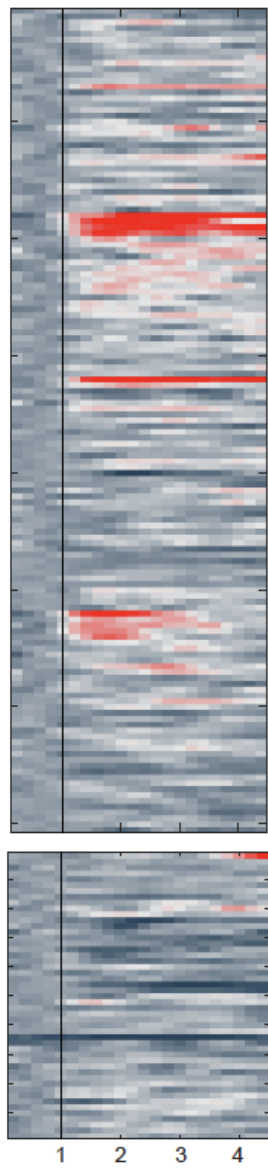

Odor 5
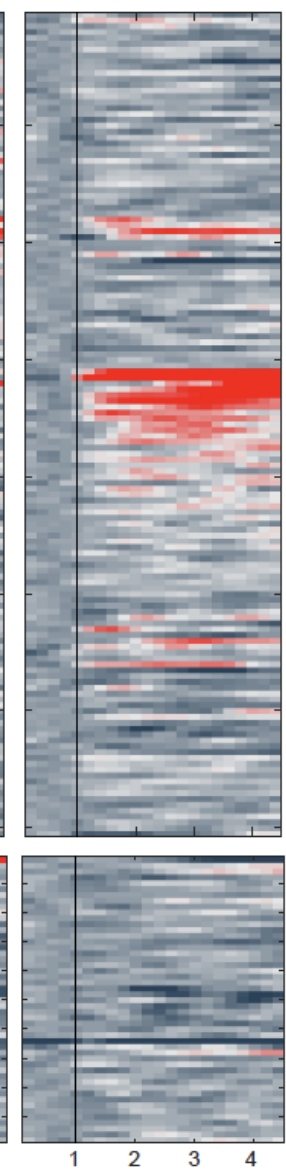

c
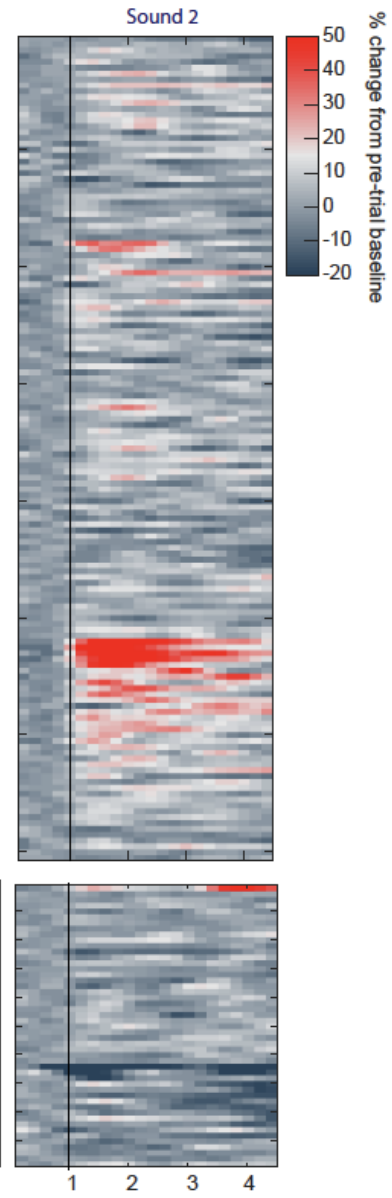

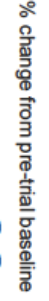

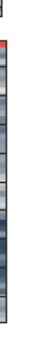

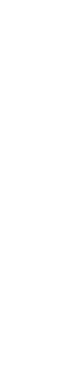

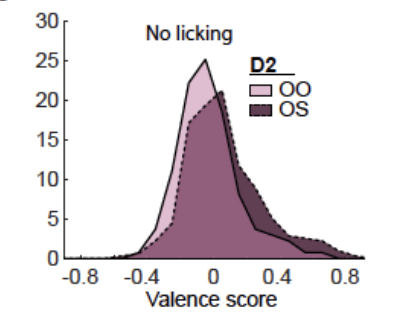

Supplementary Figure 5. D2 neuronal activity in sated Block 2 of odor-sound task with no licking and no water/airpuff outcomes. (A) D2 neuronal population activity in block 2 of day 4, in response to the learned odors and sound tones, and in the absence of licking, airpuffs, or water delivery. Neurons are grouped by preferred stimulus. Black vertical lines indicate odor onset. No outcome was delivered and only trials with zero licking were included in analysis. (B) Distributions of valence scores of D2 neurons in the odor-odor task and odor-sound task in the full task condition with licking and outcomes, (C) Same for stimulus only condition in Block 2. No significant differences were observed between these distributions. 